
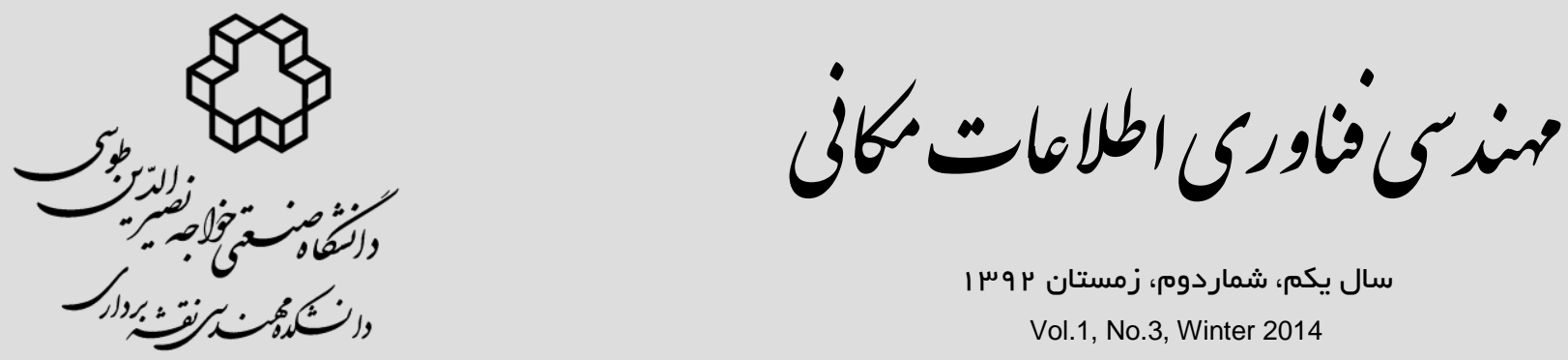

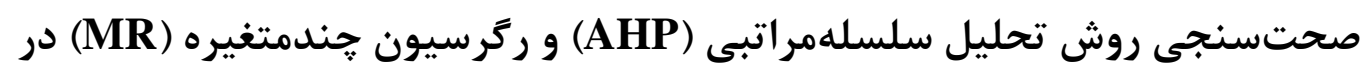

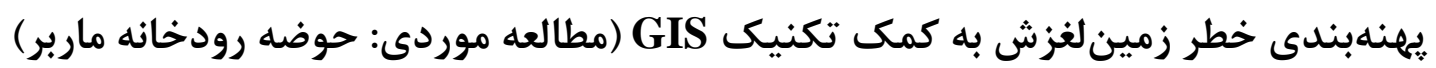

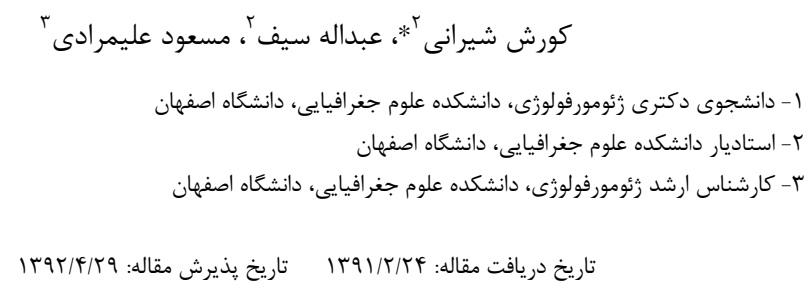

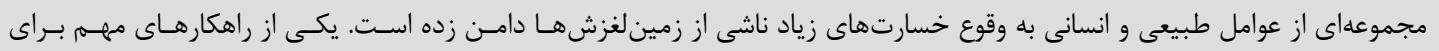

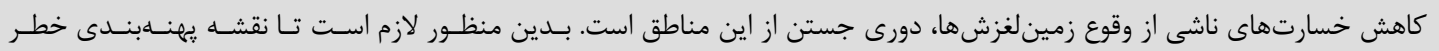

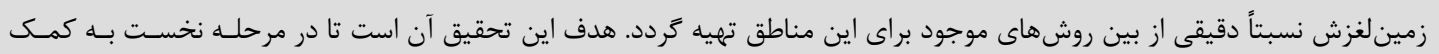

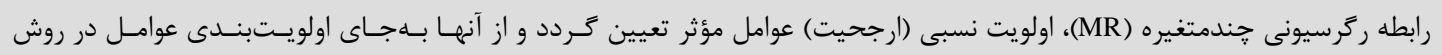

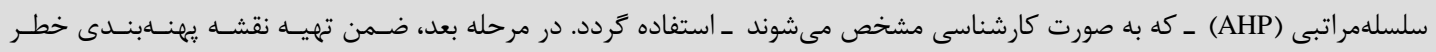

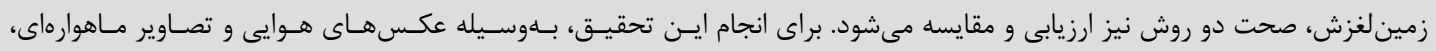

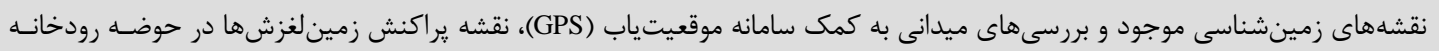

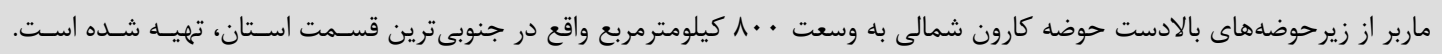

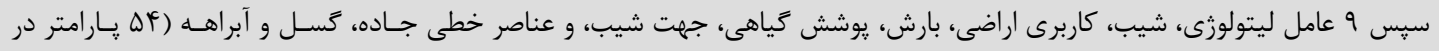

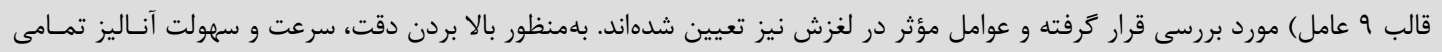

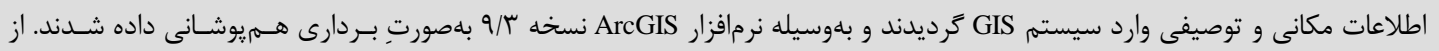

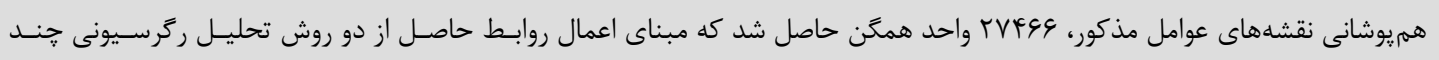

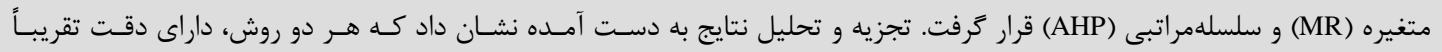

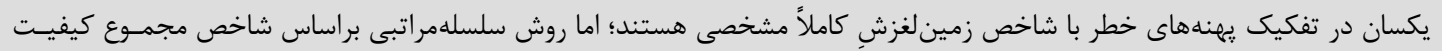

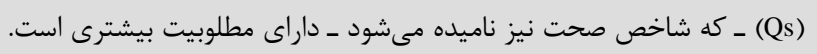
كليدوازهها: زمينلغزش، مِهنهبندى خطر، حوضه آبخيز رودخانه ماربر، ركرسيون جندمتغيره، تحليل سلسلهمراتبى (AHP)، سـامانه اطلاعـات

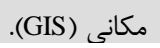


بارامترهاى طبيعى متعدد كه بهصورت همزمان و با هم

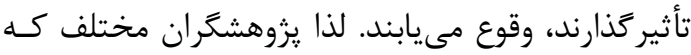

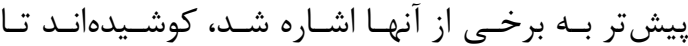

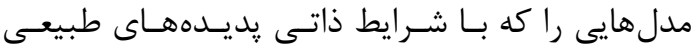
همخوانى و قرابت بيشترى دارند، به كار بخيرند.

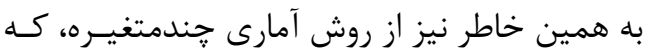
در آن عوامل طبيعى مؤثر بهعنوان متغيرهاى مسـتقل،

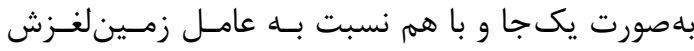

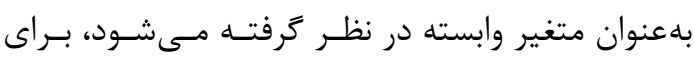

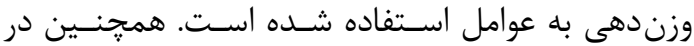

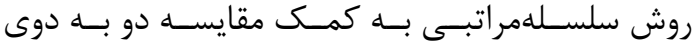

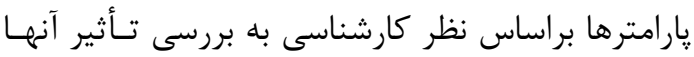

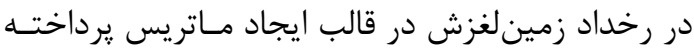

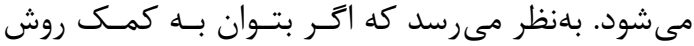

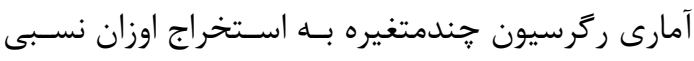

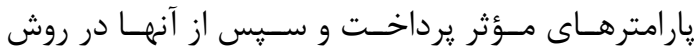

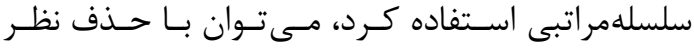
كارشناسى در اولويتبندى عوامل روش سلسلهمراتبى و

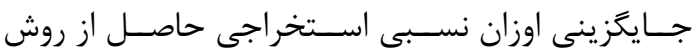
آمارى رگرسيونى بهجاى آن، دقت روش سلسلهمراتبى را بالاتر برد. لازم به ذكر است كه يزوهشكران تاكنون از

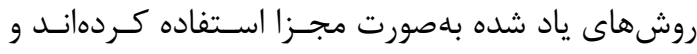

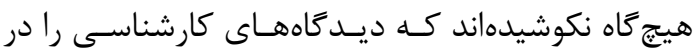
اولويتبندى و ارجحيت دادن نسبى عوامل حذف كنند.

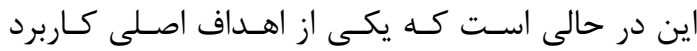

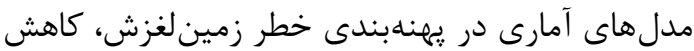

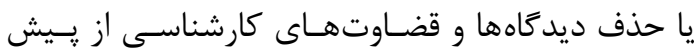
تعيين شده است.

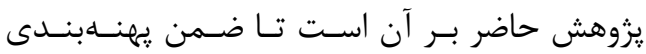

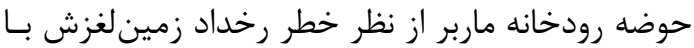

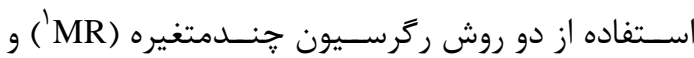

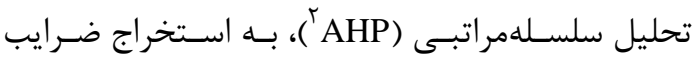

1. Multivariate Regression

2. Analytical Hierarchy Process
- 1 - - 1قدمه

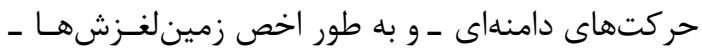

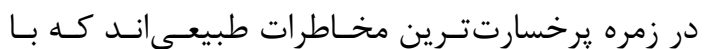

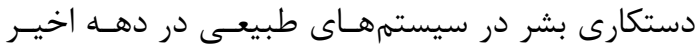

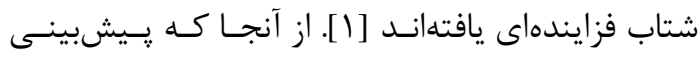

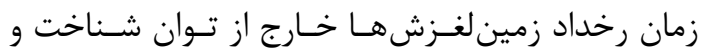

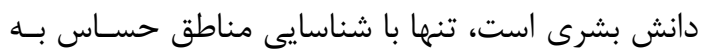
زمين لغزش و رتبهبندى كردن آنها تا حدودى مسى تـوان

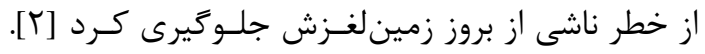

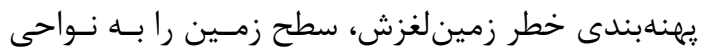

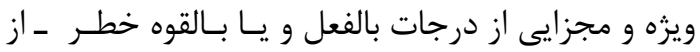

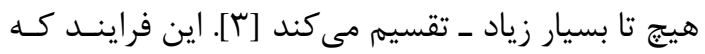
برمبناى شناخت ويرگى هاى طبيعى و مدل سازى كمّى

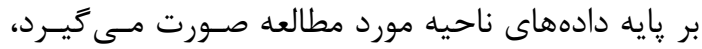

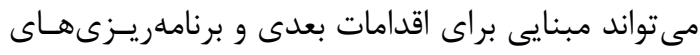
آتى توسعه و عمران در مقياس منطقـهاى و ناحيـهاى و و

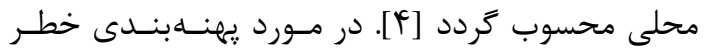
حركتهاى تودهاى تا كنون بررسىهاى زيـادى صـورت

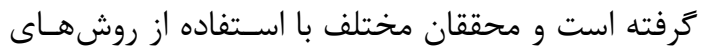
كوناكون، طبقهبنــى هــاى متــوع و متعـددى را ارائهـ كردهاند [ه]. اما بسته به وضعيت موجود منطقـهـ مـورد

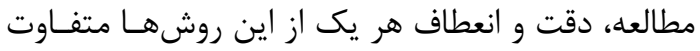
با ديخرى است. بنـابر اين بـراى شــاخت منــاطق داراى يتانسيل زمينلغزش و تهيه نقشه بهينهبندى خطر بايسد بهترين و دقيقترين روش را با توجه به عوامل مـؤثر در رخداد وضعيت منطقه بركزيد [r]]. تاكنون تحقيقات متعددى در داخل و خارج كشـور در زمينه يهينهبندى خطر زمين لغزش انجام گرفته است

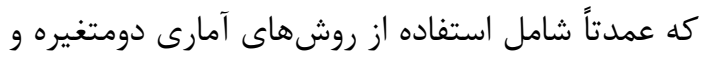

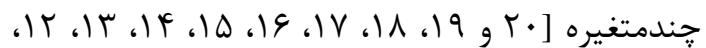

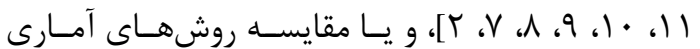

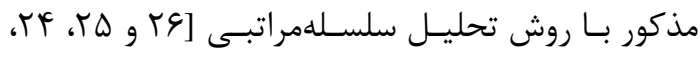

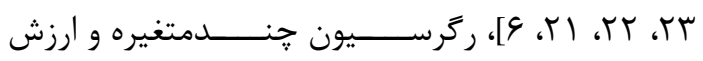

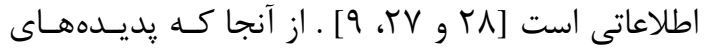
طبيعى مختلف همجحون زمين لغزش تحت تأثير و تعامل 


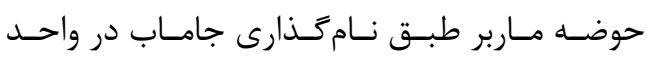

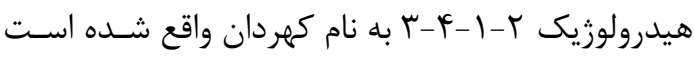

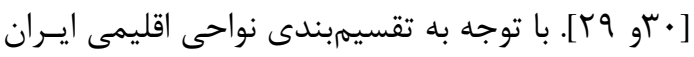

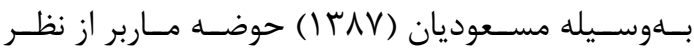

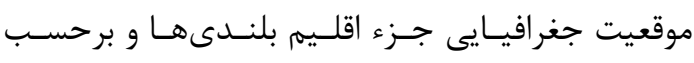

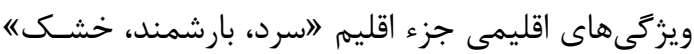

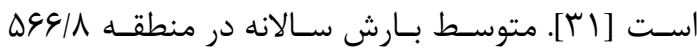

$$
\text { ميليمتر است [•r]. }
$$

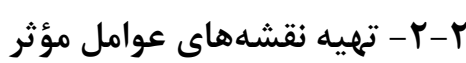

يس از زمين مرجع كردن تصاوير ماهوارهاى و نقشه هاى

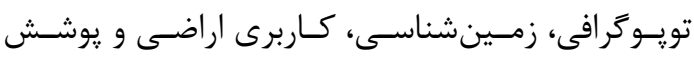

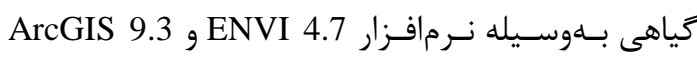

اقدام به تهيه لايههاى مورد نياز بدين شرح گرديد:

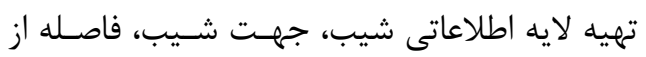

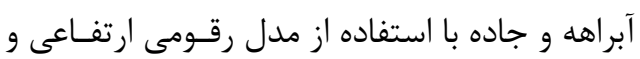
نقشـه تويـوگرافى حوضـه در محسـيط ArcGIS9.3. لازم به ذكر است كه مبناى نقشه تويوگرافى مـورد

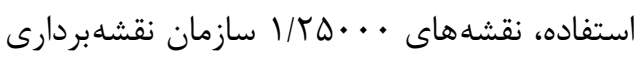

$$
\text { كشور است. }
$$

تهيه لايه اطلاعاتى ليتولـوزى و فاصـله از خسـل از از

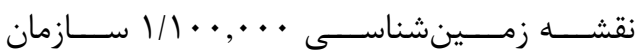
زمينشناسى كشور.

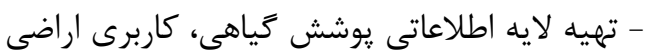

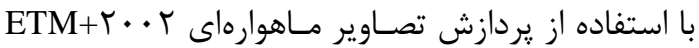

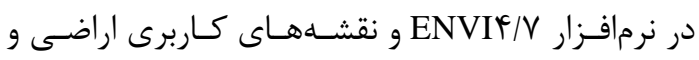

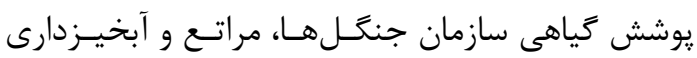

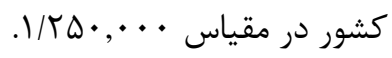

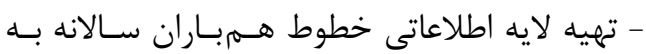

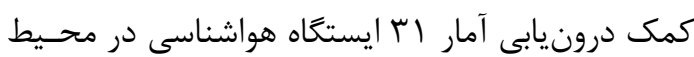
Surfer 9

- يراكنش زمين لغزش ها در منطقه مورد بررسى بـا

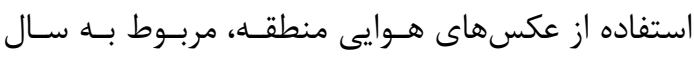

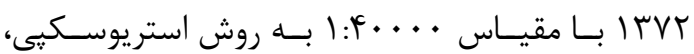
تفسير و مناطق لغزشى تعيين گرديدند. سيس موقعيت
متغيرهاى مستقل به كمك روش رگرسيون جندمتغيره به عنوان وزن كمّى عوامل مؤثر، بهجاى قضـاوت كارشناسى اهميت نسبى عوامل مؤثر در ماتريس تحليل سلسلهمراتبى (AHP) بيردازد و در نهايت ضمن ارزيابى مؤى دو روش مذكور، ميزان دقت آنها را تعيين كند.

\section{r - مواد و روشها} r-1 - منطقه مورد مطالعه

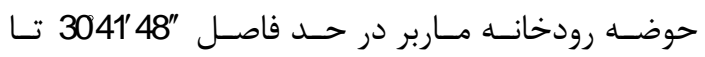

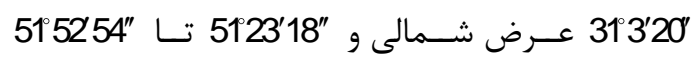
طول شرقى واقع شده است. وسعت حوضه ماربر حسدود

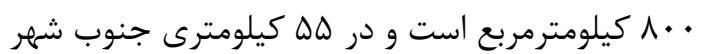
سميرم قرار دارد. اين حوضـهـ در جنـوبى تـرين قسـمت

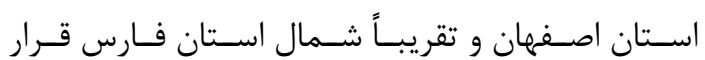
مى گيرد.

ناحيه مورد نظــر در سلسـلهجبـال زاخـرس در زون زاگرس مرتفع جاى كرفتــه اسـت و در واقـع بـه دليـل عملكرد راندگى دنا، بيده و كوه سـياه ناگمهـان بـه يـيكـر بلندى در كنار و موازى بخش زاگرس جين خورده قـرار دارد [ץ]. بالاترين ارتفاع منطقه . . rأ متر و يايينترين ارتفاع آن به I9VI متر مىرسد. منطقــه مـورد مطالعـه

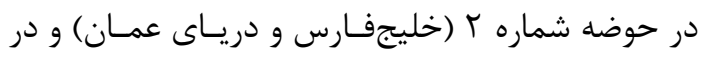
دامنه شمال شرقى قله دنا واقع شده است (شكل (1).

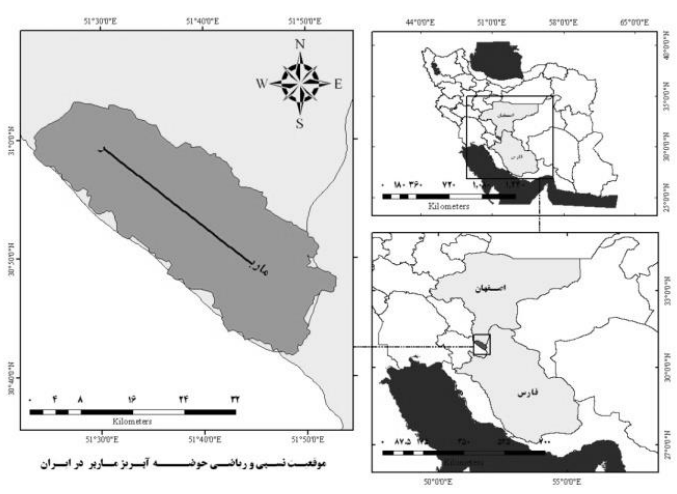

شكل ا. موقعيت جغرافيايى حوضه رودخانه ماربر واقع در يادناى علياى سميرم اصفهان 


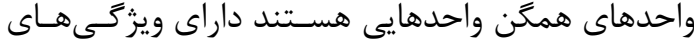

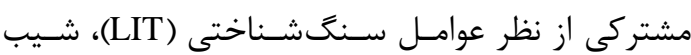

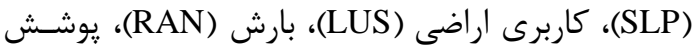

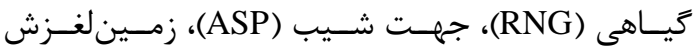

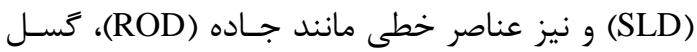

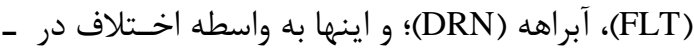

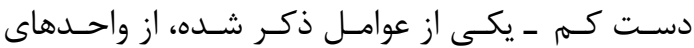
مجاورشان تمايز مى يابند. به ايـن ترتيـب در مـورد هـر

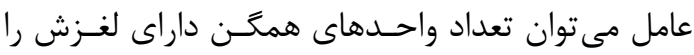

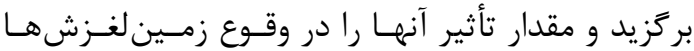
بررسى كرد و به مقدار كمّى بدل ساخت [r/r].

r-r-r-r-r كمّى كردن عوامل مؤثر، و وزن دادن به آنها متغيرهاى مورد استفاده در تحليل خطر زمين لغزش در

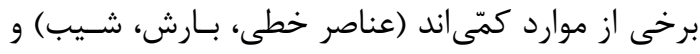

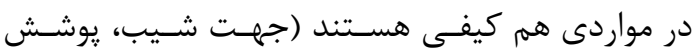

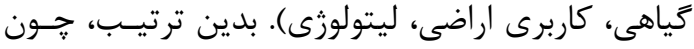

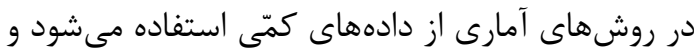

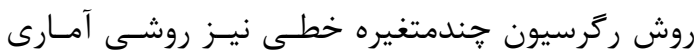

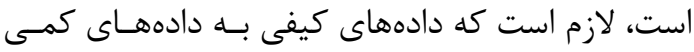

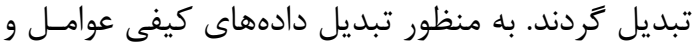

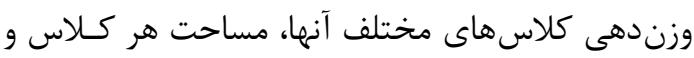
درصد سطح لغزشيافته آن با واحدهاى همخن محاسبه

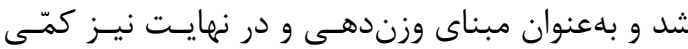
كردن يارامترها در ركرسيون جندمتغيره به كار بار رفت

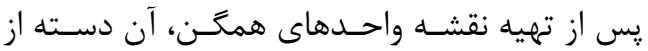

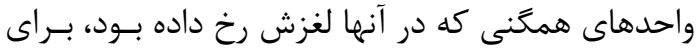

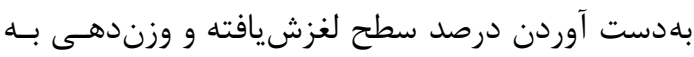

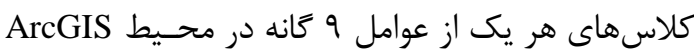

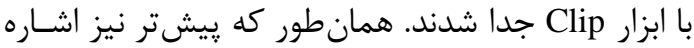
شد، كلاسهبندى عامل شيب و بارش و عناصر خطى بـا توجه به شكست هاى طبيعى نمـودار فراوانى تجمعى دارى بهدست آمدند و براى ديخر عوامل از محتويـات موجــود در هر نقشه استفاده شد. سيس جدول كلاسهبندى هـر

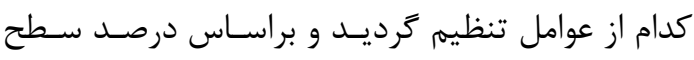

دقيقتر لغزشها با استفاده از بررسى هـاى صـحرايى و

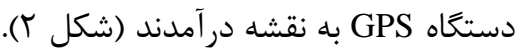

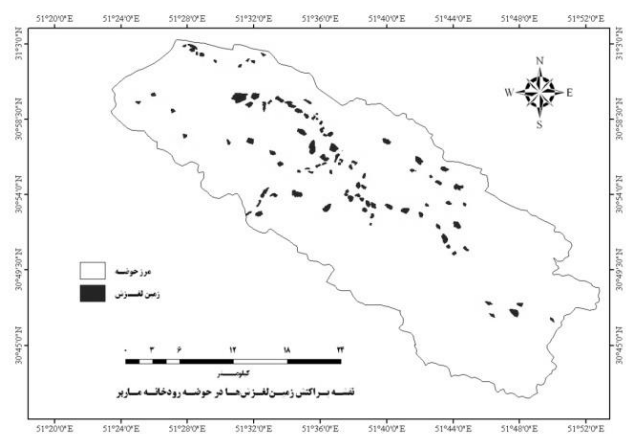

شكل r. يراكنش زمين لغزشهاى حوضه رودخانه ماربر واقع در يادناى علياى سميرم اصفهان

لازم به ذكر است كه براى بهدست آمدن واحـدهاى

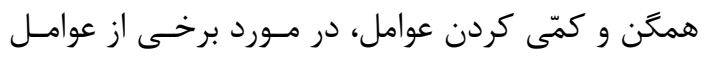

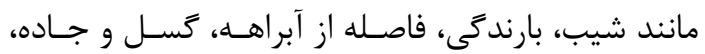
نقشه هر عامل (بهصورت محـدودههـاى بـافر از عناصـر خطى) با توجه به ويزَّى هاى آن عامل و بــا اسـتفاده از

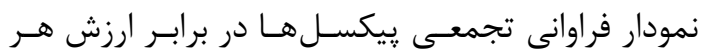
ييكسل استفاده شده است. بر روى اين منحنى مناطقى بئى

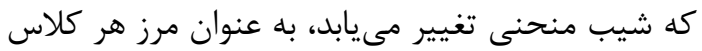

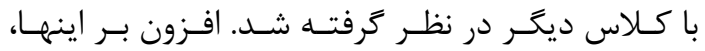

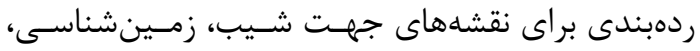
كاربرى اراضى، و يوشش كياهى ـ با توجه به محتويـات

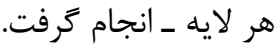

r-r- انجام روش ركرسيون جندمتغيره (MR)، با استفاده از دادههاى كسسته ץ-ץ-1- تعيين واحدهاى همكن به منظور يهنهبندى خطر زمين لغزش در حوضه ماربر با

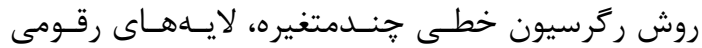

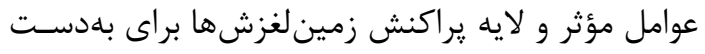
آمدن نقشه واحدهاى همخن در محيط GIS و بهوسـيله

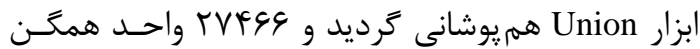

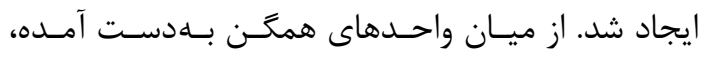

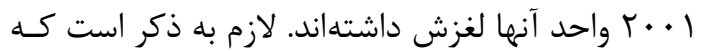


معنى دار، و ضريب همبستخى (R) آنها DV • • بوده است.

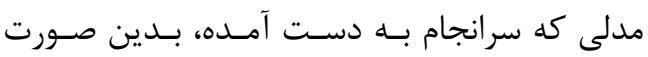

رابطه (1)

$\mathrm{Y}=\mathrm{B} \circ+\mathrm{B} 1 * \mathrm{X} 1+\mathrm{B} 2 * \mathrm{X} 2+\ldots+\mathrm{Bn} * \mathrm{Xn}$

= متغير وابسته (رخداد زمين لغزش واحد همگً) Y خط ض0 خطى، كه در اين تحقيق صفر به دست آمد.

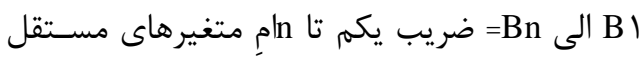
(عوامل مؤثر طبيعى) معادله رگرسيون خطى.

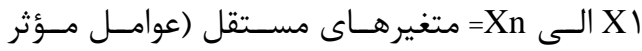
طبيعى) معادله رگرسيون خطى.

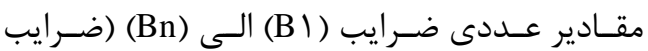
رَرسيونى) و همجنين متغيرهاى مستقل (عوامل مـؤثر

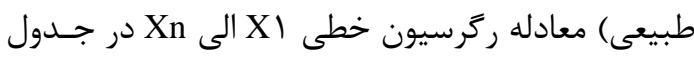

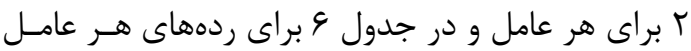

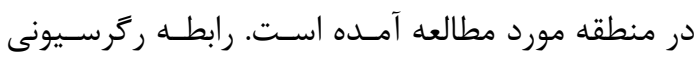

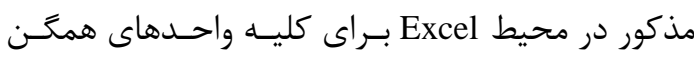
اعمال گرديد، و وزن هاى بلهدست آمده بــراى واحــدهاى

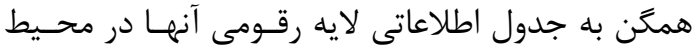
GIS

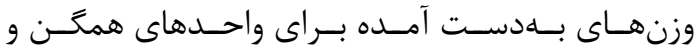
همجنين بهمنظور مقايسه منطقى نتيجه بهدست آمـده

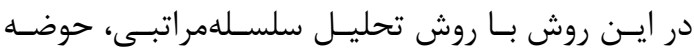

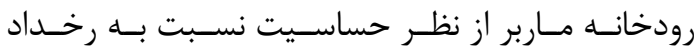
زمينلغزش به ه كـلاس تقسـيم ترديــد (جــدول () ) و نقشه يهنهابندى خطر زمين لغزش در حوضه به با اسـتفاده

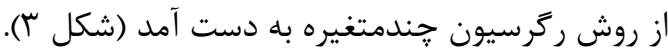
جدول 1. گسترههاى لغزشى حوضه رودخانه ماربر در روش ركرسيون جندمتغيره

\begin{tabular}{|c|c|}
\hline گسترههاى با حساسيت خيلى كم & $\mathrm{Y}<11$ \\
\hline گسترههاى با حساسيت كم & $11<Y<r$. \\
\hline گَسترهاى با حساسيت متوسط & $r \cdot<Y<r q$ \\
\hline گسترههاى با حساسيت زياد & $r q<Y<r$. \\
\hline كسترههاى با حسايت خيلى زياد & $r \cdot<Y$ \\
\hline
\end{tabular}

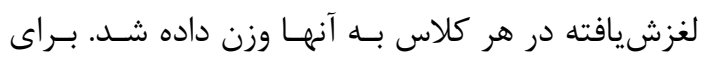

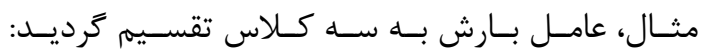

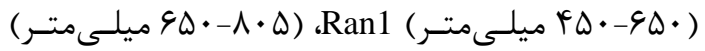

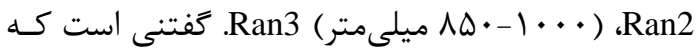

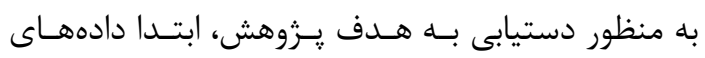

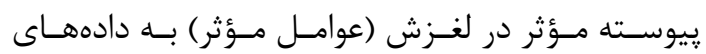

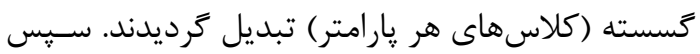
از نسبت مساحت سطح لغزشيافته به مساحت كل هـر كلاس، بهعنوان مبناى وزندهى و نهايتـاً كمّى كـردن يارامترها (به كمك رگرسيون جندمتغيره) استفاده شد.

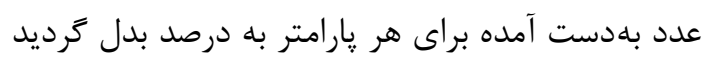

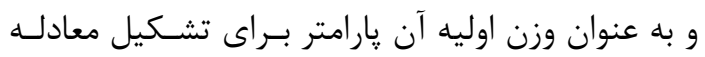
رگرسيونى در نظر زرفته شد. بديهى است هر جه

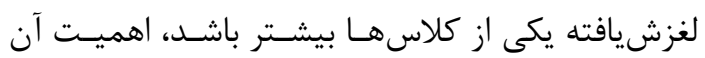

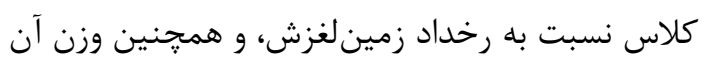

بيشتر خواهد بود.

\section{r-Y-r-r- تجزيه و تحليل آمـارى و انجـام رابطــهـ ركرسيونى بين عوامل}

به منظور انجام رگرسيون جندمتغيره بين عوامل مـؤثر، يس از بهدست آوردن وزنهاى اوليه كلاسهاى مختلف رئف هر يك از عوامل، اطلاعات به محيط SPSS وارد شـدند،

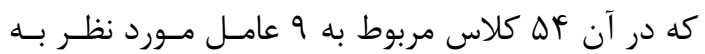

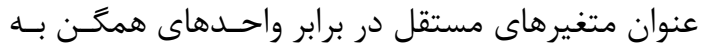

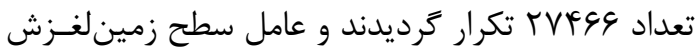
در هر واحد همخَن بـه عنـوان متغيــر وابسـته در نظـر

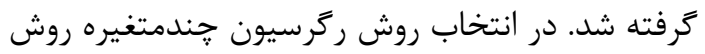
كام به كام (Stepwise) انتخاب شد كه نتايج حاصـل از

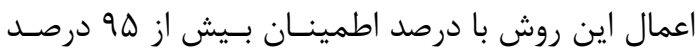
تعيين گرديد. يس از انجام عمليات رگرسيونى از ميـان

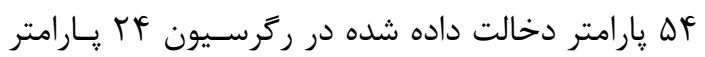
به دليل داشتن ضريب معنى دارى كمتر از هو درصـد و لهـ نداشتن رابطه آمارى قوى با درصد سطح لغزشهاى رخ

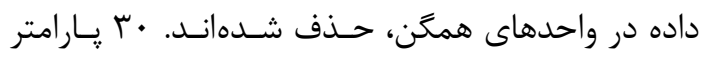

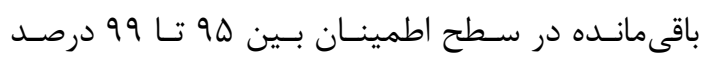




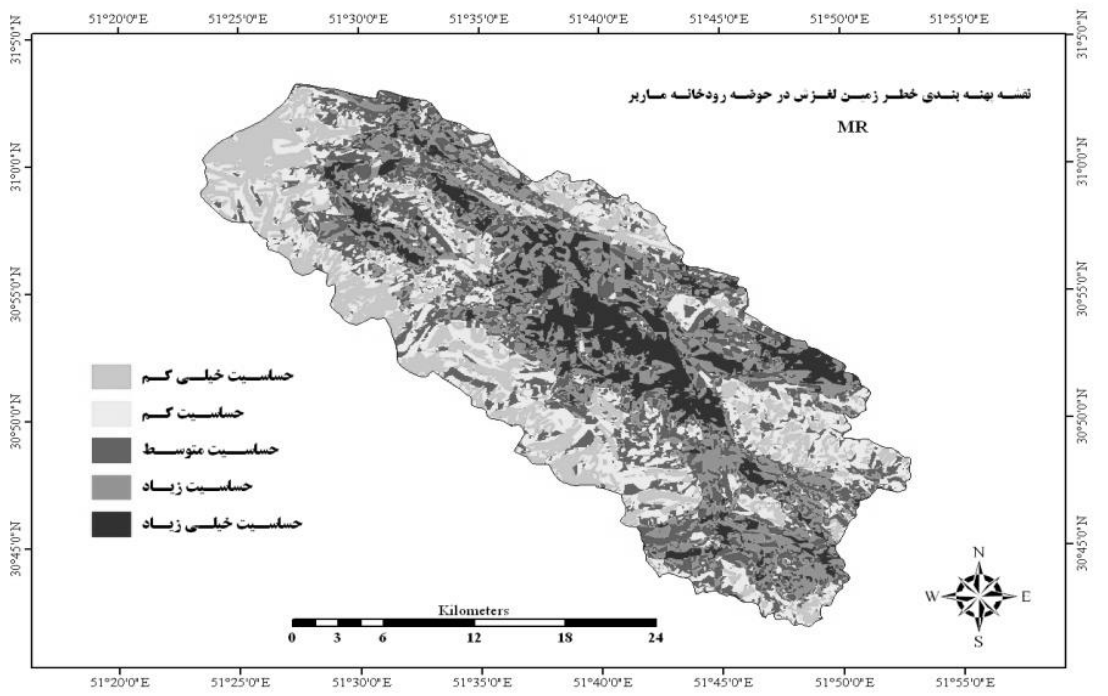

شكل س. نقشهُ يِهنهبندى خطر زمينلغزش در حوضه رودخانه ماربر به روش ركرسيون جندمتغيره (MR)

اولويتبندى و محاسبه وزن نسبى يارامترهـا از ضـريب

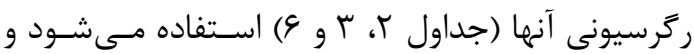
ديخر نظر كارشناسى اعمـال نمسى گـردد. در ايسن روش

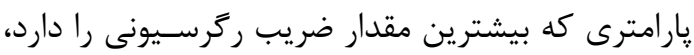
بيشترين اهميت يا ارجحيت را نيز نسبت به هدف دئ دارد؛ و در ماتريس مقايسه زوجى بالاترين اولويت يعنى عـدد

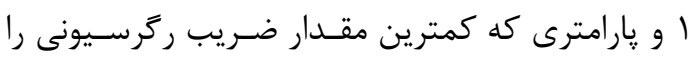

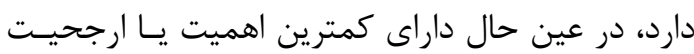

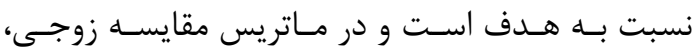
يايينترين اولويت ـ يعنى عدد 9 ـ را به خود اختصـاص

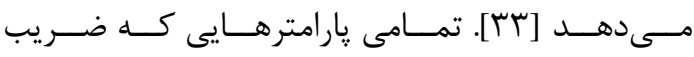

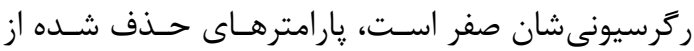
معادله ركرسيونى اند و بــراى آنهـا در مـاتريس، اولويست

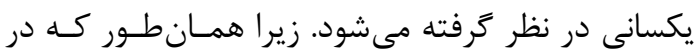
مبحث روش ركرسيون خطى بيان زرديد، مقدار ضريب ريب

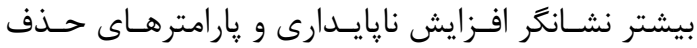
شده كه داراى ضريب صفرند، نسبت به هـدف (رخــداد

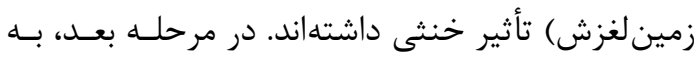
تشكيل ماتريس مقايسه زوجى عوامل (جدول ب) و نيـز

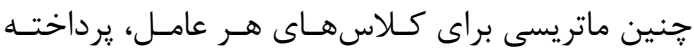

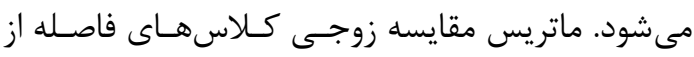

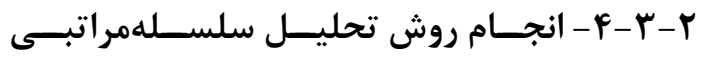

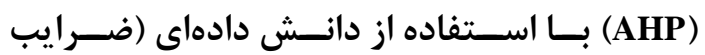

\section{(َ)}

ساختار سلسلهمراتبى به كار رفته در اين روش، با آنجــهـ

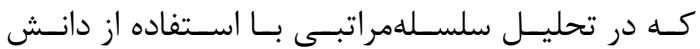

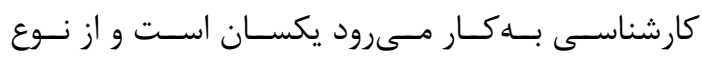

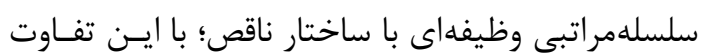

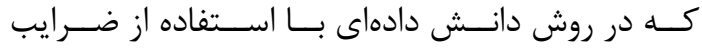

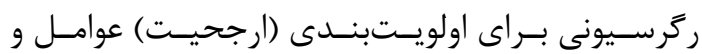
محاسبه وزن نسبى ڤارامترها از ضرايب رگرسيونى آنهـا (جدول r) استفاده نمىشود و نظر كارشناسى به منظور اولويتبندى عوامل يا ردههاى آنها، اعمـال نمسى گــردد. نكته درخور توجـهـ در ايسن روش آن اسـت كــه مقـادير

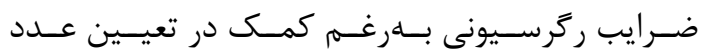
اولويتبنـدى (ارجحيـت) نسـبى عوامـل، مسىتوانـد در تعيين فواصل يا نرخ ارجحيت در تحليل سلسلهمراتبـى لونى تأثير گذار باشد.

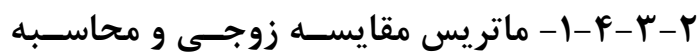

$$
\text { وزن آيتمها (عوامل و كلاسها) }
$$

همان طور كه اشاره شـد، در روش دانـش دادهاى بــــاى 
دارد، بلدست آيد. در جدول \& أنتايج حاصل از نرمـاليزه

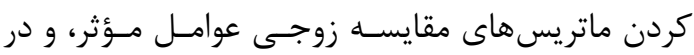
جدول ه نيز زير عامل ها يا كلاسهـاى فاصـله از جـاده

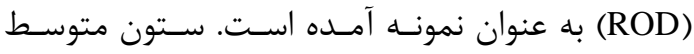

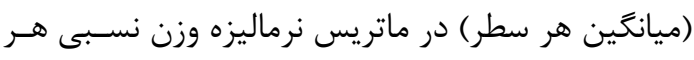
عنصر را نشان مىدهد.

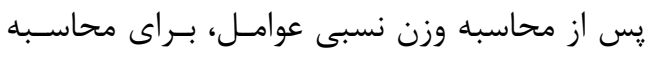

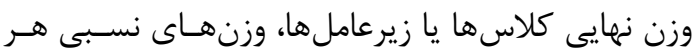

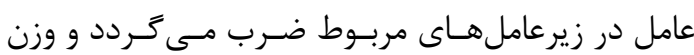
نهايى زيرعاملها براى تحليل سلسلهمراتبى بـه كمـك ردي

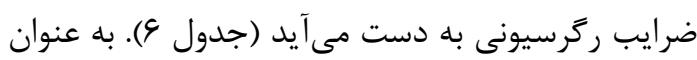

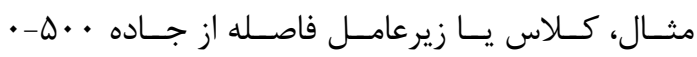
(RODI)

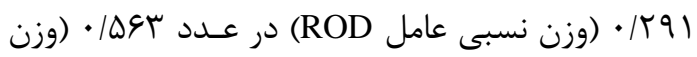

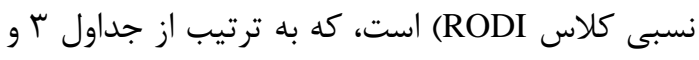

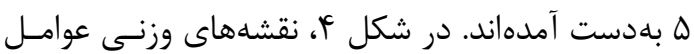
مؤثر نشان داده شده است.
جاده (ROD) با ץ كلاس جدول ץ بهعنوان نمونه آمـده

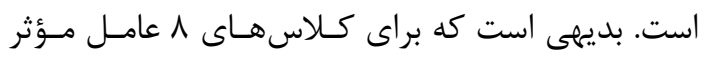
ديكر نيز به همين صورت اقدام مى رَردد. يس إن از تشكيل

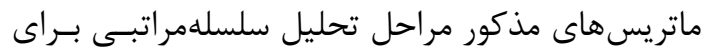

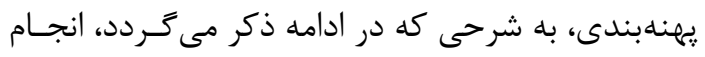

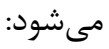

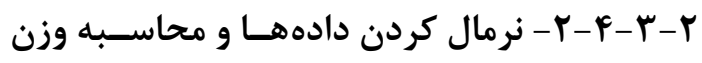
عوامل و كلاسها

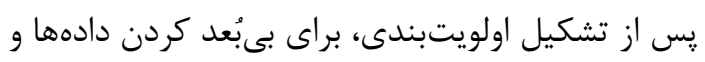

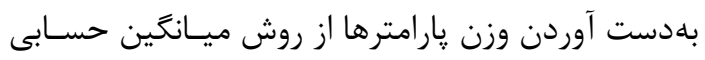

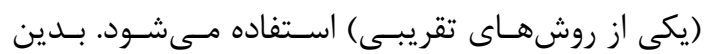

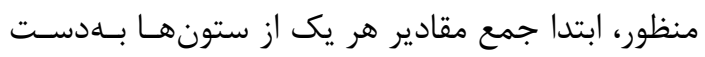

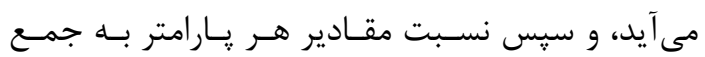

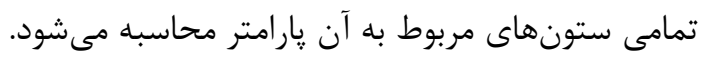

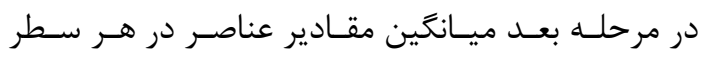
محاسبه مى گَردد تا وزن يارامترى كه در آن سطر قـر مرار

جدول r. ماتريس مقايسه زوجى عوامل مؤثر در رخداد زمين لغزش در حوضه رودخانه ماربر

\begin{tabular}{|c|c|c|c|c|c|c|c|c|c|c|}
\hline ضريب ركرسيونى & معيار ها & ROD & LIT & RNG & DRN & LUS & SLP & ASP & RAN & FLT \\
\hline - IrFA & ROD & 1 & 1 & f & f & $\Delta$ & 9 & V & 9 & 9 \\
\hline . & LIT & 1 & 1 & r & r & f & $\Delta$ & 4 & 9 & 9 \\
\hline$\cdot / \cdot r \cdot \Lambda$ & RNG & $\cdot / \pi \Delta \cdot$ & אسז/. & 1 & 1 & r & f & $\Delta$ & v & v \\
\hline$\cdot / \cdot r \cdot r$ & DRN & $\cdot / \pi \Delta$. & אחץ/. & 1 & 1 & r & r & F & 9 & 9 \\
\hline$. / \cdot \mid \Delta F$ & LUS & $\cdot / \pi \cdot$ & $\cdot / T \Delta \cdot$ & זוזא/. & $\cdot / \Delta \cdot \cdot$ & 1 & r & $r$ & $\Delta$ & $\Delta$ \\
\hline$\cdot / \cdot 1 \cdot V$ & SLP & $\cdot / 19 \mathrm{~V}$ & $\cdot / \pi \cdot \cdot$ & $\cdot / T \Delta \cdot$ & אזسאן & $\cdot / \Delta \cdot \cdot$ & 1 & r & r & r \\
\hline$\cdot / r \cdot$ & ASP & T &.$/ 19 V$ & $\cdot / T \cdot \cdot$ & $\cdot / r \Delta \cdot$ & אוז"/. & $\cdot / 0 \cdot \cdot$ & 1 & $r$ & r \\
\hline$-\cdot / \cdot T \Delta V$ & RAN & $\cdot / 111$ &.$/ 111$ & . / F & $\cdot / 19 \mathrm{~V}$ & $\cdot / T \cdot$ & זוז/. & $\cdot / \Delta \cdot \cdot$ & 1 & 1 \\
\hline$-\cdot / \cdot \operatorname{FVT}$ & FLT & $\cdot / 111$ &.$/ 111$ &.$/ \mathrm{FH}$ & $\cdot / 19 V$ & $\cdot / T \cdot \cdot$ & זrת/. & $\cdot 10 \cdot \cdot$ & 1 & 1 \\
\hline & مجموع & T/THT & $r / \Delta \cdot \varphi$ & 1.1 .99 & $1 \cdot / 4 I V$ & 19/TrM & KT/GV & rq & pr & pr \\
\hline
\end{tabular}


جدول r. ماتريس مقايسه زوجى كلاسهاى فاصله از جاده (ROD)

\begin{tabular}{|c|c|c|c|c|c|}
\hline ضريب رَرسيونى & فاصله از جاده (متر) & $($ ROD1) $\bullet-\Delta \cdot \bullet$ & (ROD2) $\Delta \cdots-1 \cdots \cdot$ & $($ ROD3 $) 1 \cdots-\Delta \cdots$ & (ROD4) $\Delta \cdots<$ \\
\hline •/rr人. & $($ ROD1) $\cdot-\Delta \cdot \cdot$ & 1 & r & $\Delta$ & V \\
\hline$\cdot / I \vee \Delta \cdot$ & $($ ROD2) $\Delta \cdots-1 \cdots$ & אח שח/. & 1 & r & $\Delta$ \\
\hline$\cdot 1 \cdot 9 \cdot 9$ & $($ ROD3) $) \cdots-\downarrow \cdots$ & $\cdot / T$ & س سז/. & 1 & $r$ \\
\hline \multirow[t]{2}{*}{ •l/ror } & $($ ROD4) $\Delta \cdots$ & $\cdot / \mathrm{FT}$ & $\cdot / 4$ & $\cdot / \Delta$ & 1 \\
\hline & مجموع & 1/9V9 & T/DH & $9 / 0$ & 10 \\
\hline
\end{tabular}

جدول F. ماتريس نرمال دادهها و محاسبه وزن عناصر با استفاده از روش ميانگين حسابى

\begin{tabular}{|c|c|c|c|c|c|c|c|c|c|c|}
\hline معيار ها & ROD & LIT & RNG & DRN & LUS & SLP & ASP & RAN & FLT & ميانگين(وزن \\
\hline ROD & $\cdot / r \cdot q f$ & $\cdot / r \wedge \Delta K$ & ש & . / r & $\cdot / \mu \cdot \Lambda \cdot$ & $\cdot / T V \cdot V$ & $\cdot / T F \mid F$ & $\cdot / r \cdot q r$ & $\cdot / r \cdot q r$ & $\cdot / r q 1$ \\
\hline LIT & $\cdot / r \cdot q 4$ & $\cdot / r \wedge \Delta \Gamma$ & $\cdot / / q \vee q$ & $\cdot / r \wedge \Lambda \cdot$ & - MYGSF & - /TTAG & $\cdot / \pi \cdot 99$ & r. & r. & - $/ T \Delta K$ \\
\hline RNG & $\cdot / \cdot V V F$ & .1 .901 &.$/ .994$ & .1 .99$. & $\cdot / A K A$ & $\cdot / \Lambda \Lambda \cdot \Delta$ & - IIVYF & . /IGTA & - /IGYA &.$/ M V$ \\
\hline DRN & $\cdot / \cdot V V F$ &.$/ .9 \Delta 1$ &.$/ .994$ &.$/ .94$. & אTr & r &.$/ 1 r v q$ & ט & ט & .1119 \\
\hline LUS & .1 .919 & r. & וسץ.•. &.$/ \cdot \psi_{\lambda} \wedge$. & .1 .919 & $\cdot / \cdot q \cdot r$ & $\cdot / 1 \cdot r F$ & . /IIG & $\cdot / \| q \mu$ & $\cdot / \cdot \vee \wedge$ \\
\hline SLP & $\cdot / \cdot \Delta 19$ & $\cdot / \cdot \Delta V I$ &.$/$ TYA & . /.TK. & $\cdot / \cdot r \cdot \Lambda$ & $\cdot|\cdot| c \Delta \mid$ & .1 .99$. & .1 .991 & .1 .991 & $\cdot / \cdot \Delta \cdot$ \\
\hline ASP & - I. FET &.$/$. FVG & .1 .199 & . I. rY. & $\cdot / \cdot r \cdot \Delta$ & . ITKG & . I. MFD & $.1 \cdot \forall \& \Delta$ &.$/ .4 \& \Delta$ &.$/ \cdot r F$ \\
\hline RAN & . I. MAF & •/. KIV &.$/ .1 F T$ & .1 .19$. & אזו •/. & $\cdot / \cdot 10$. & $.1 \cdot 1 \mathrm{VT}$ & זrז./. & זrז./. & $\cdot \mid \cdot r I$ \\
\hline FLT & . I. MAF & . &.$/ .1 F T$ &.$/ .19$. & אזו./. &.$/ \cdot 10$. & $.1 .1 \mathrm{VT}$ & ת Tr./ & אזr./. & $\cdot|\cdot r|$ \\
\hline مجموع & 1 & 1 & 1 & 1 & 1 & 1 & 1 & 1 & 1 & 1 \\
\hline
\end{tabular}

جدول ه. ماتريس نرماليزه كلاسهاى فاصله از جاده (ROD)

\begin{tabular}{|c|c|c|c|c|c|}
\hline فاصله از جاده (متر) & $($ ROD1) $\bullet-\Delta \cdot \bullet$ & (ROD2) $\Delta \cdots+-1 \cdots \cdot$ & (ROD3) $1 \cdots-\downarrow-\downarrow \cdots$ & (ROD4) $\Delta \cdots \bullet$ & (وزن نسبى كلاس) \\
\hline$($ ROD1) $\cdot-\omega \cdot \cdot$ & $\cdot / 09 \mathrm{~V}$ & . 1994 & - /DTE &.$/ 4 \& V$ & . IDST \\
\hline$($ ROD2) $\Delta \cdots-1 \cdots$ &.$/ 199$ & $\cdot / 4 T I$ & ( & س זسא• & - KSV \\
\hline$($ ROD3) $) \cdots-\downarrow \cdots$ & .1119 & $\cdot / \cdot v^{f}$ & $\cdot / 1 \cdot \Delta$ & תות - (1/. & $\cdot / 1 \cdot 1$ \\
\hline (ROD4) $\Delta \cdots<$ & $\cdot / \cdot \wedge \Delta$ & $\cdot / \cdot p q$ & $\cdot / \cdot \Delta r$ & $.1 .9 V$ &.$/ .94$ \\
\hline مجموع & 1 & 1 & 1 & 1 & 1 \\
\hline
\end{tabular}




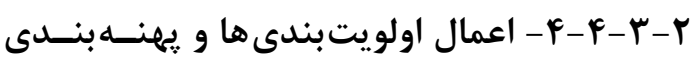

\section{حوضه}

براى بهدست آمدن مدل نهايى يا نقشه يهنهابندى، ابتدا

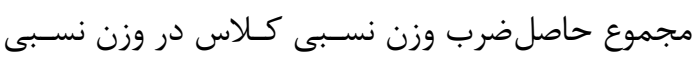

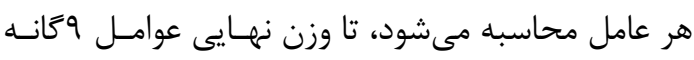

بلهدست آيد (رابطه عأ).

$$
\text { (i) (1) }
$$

$\mathrm{W}=((\mathrm{C} 1 \mathrm{X})+(\mathrm{C} 2 \mathrm{X})+$ $+(\mathrm{Cn} . \mathrm{X}))$

$$
\begin{aligned}
& \text { = وزن نهايى عامل، } \\
& \text { = وزن نسبى كلاس، } \\
& \text { X }
\end{aligned}
$$

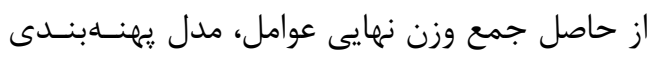

$$
\text { استخراج مى گردد (رابطه هاهل. }
$$

$$
\text { رابطه (ه) }
$$

$\mathrm{M}=(\mathrm{W} 1+\mathrm{W} 2+\ldots \ldots .+\mathrm{Wn})$

= مدل نهايى، M وزن نهايى عوامل =

براى انجام محاسبات ياد شده و اعمال صحيح اوزان

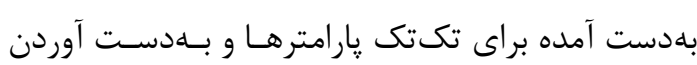

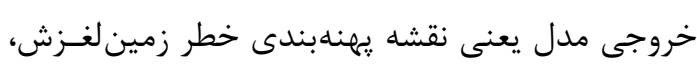

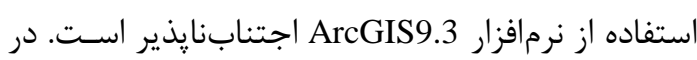

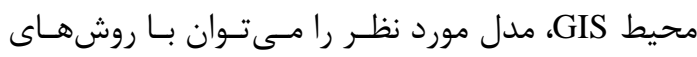

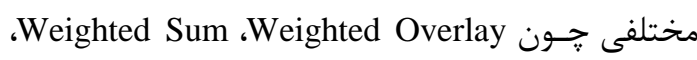
Raster Calculator gxtention AHP

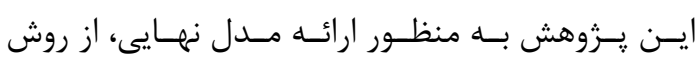

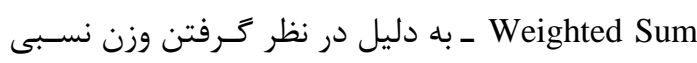

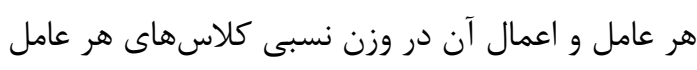

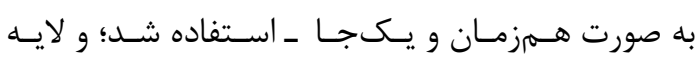

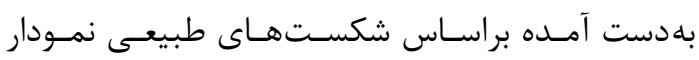

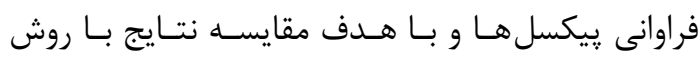
ركرسيون קندمتغيره به له كلاس لغزشى تقسيم كرديد

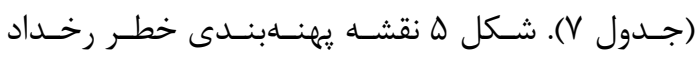

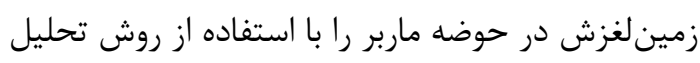
سلسلهمراتبى با دادههاى كمّى، نشان مى دهد.

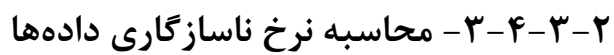

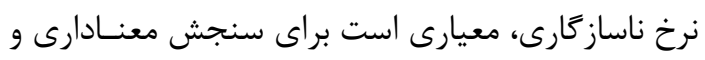

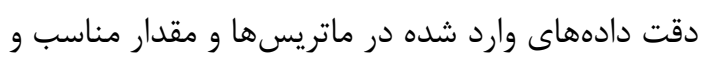

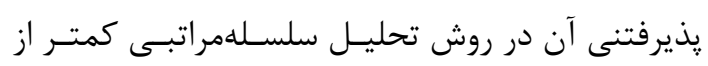

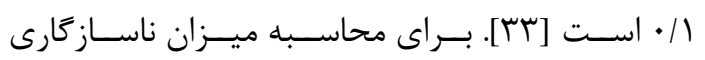

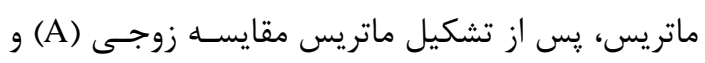

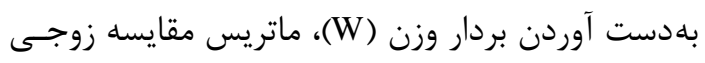

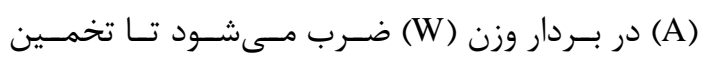

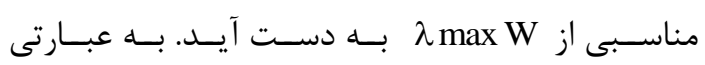

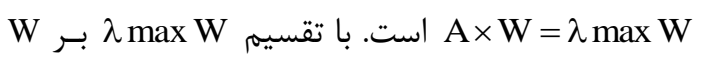

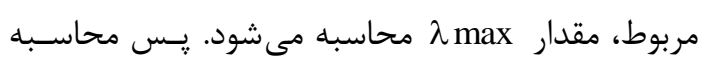

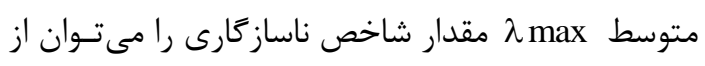

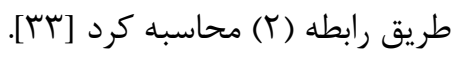

رابطه (r)

I.I. $=\frac{\lambda \max -n}{n-1}$

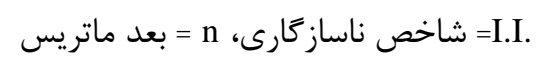

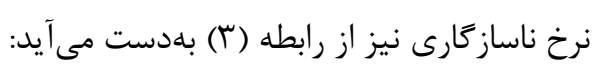

رابطه (r)

I.R. $=\frac{\text { I.I. }}{\text { I.I.R. }}$

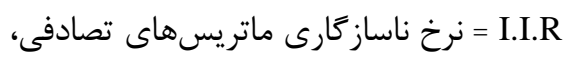

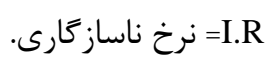

بدين ترتيب، براى محاسبه نرخ ناسازكارى دادهها از

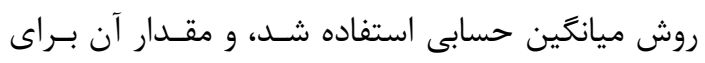

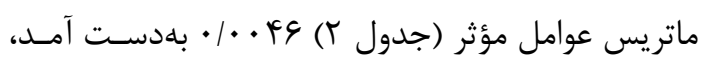
كه يذيرفتنى است.

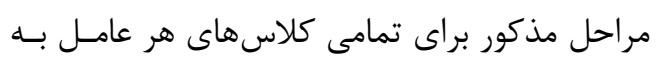

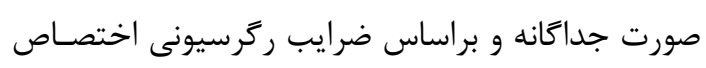

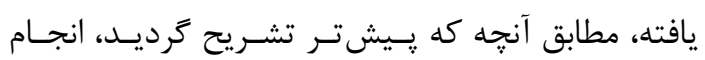

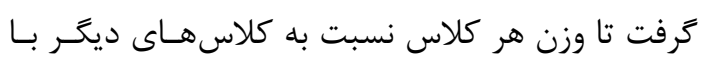

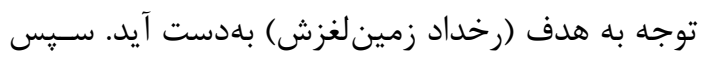

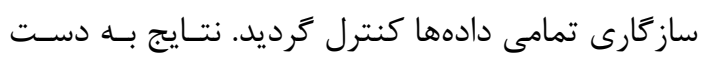
آمده، در جدول 9 نشان داده شده است. 

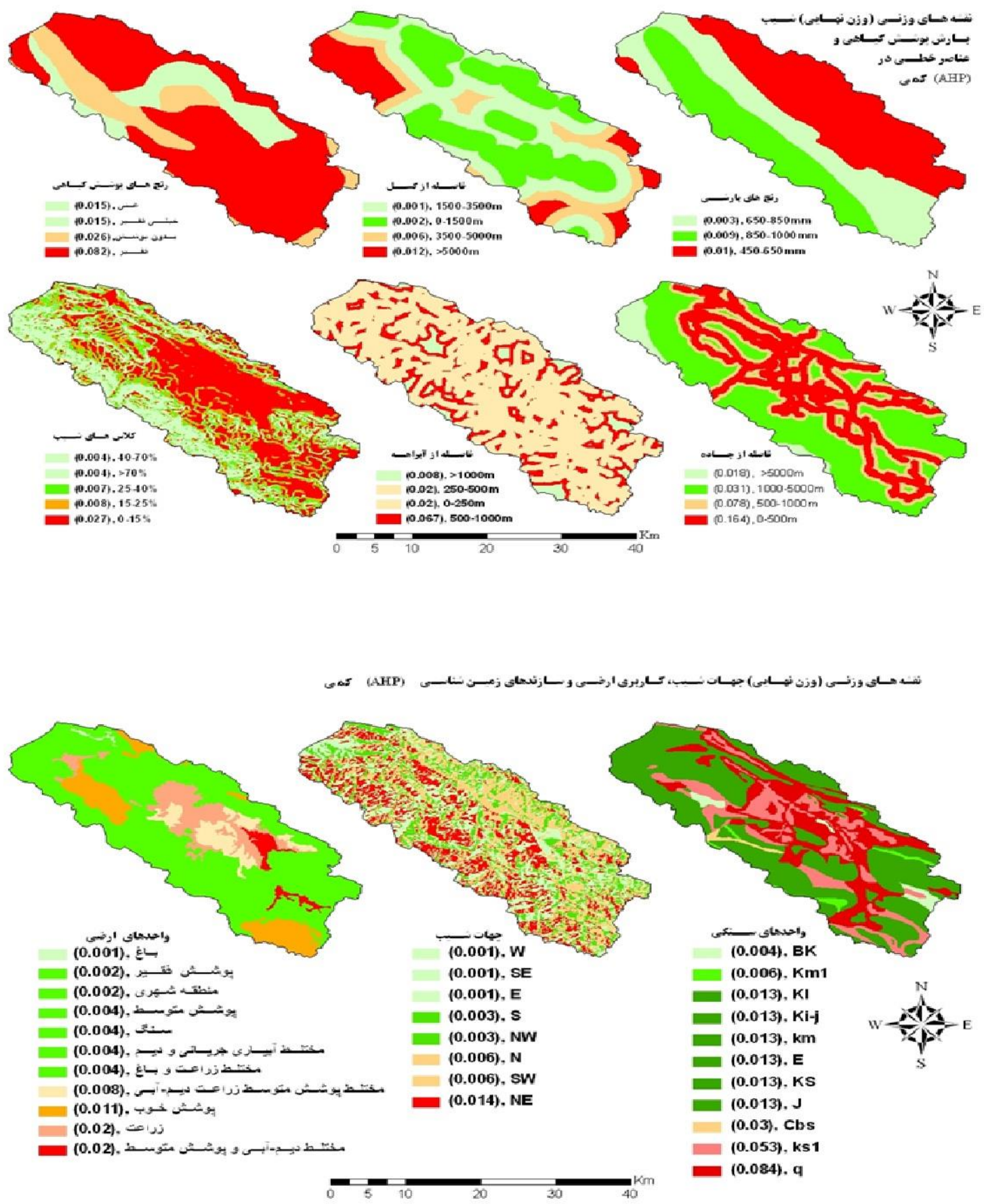

شكل F. نقشه وزنى عوامل مؤثر به روش AHP با استفاده از ضرايب ركرسيونى 
جدول 9. نتايج بهدست آمده براى هر كلاس يس از طى مراحل سلسلهمراتبى

\begin{tabular}{|c|c|c|c|c|c|c|c|c|c|c|c|c|c|}
\hline عامل & عنبي & كد كلاس & كالاس & ركرسيوني & كلاسب & نهايي & كد عامل & عنبي & | كد كلاس & نام كلاس & ضريب ركرسيوني & كلاسبي & نهايي \\
\hline \multirow{4}{*}{ ROD } & \multirow{4}{*}{$r 91 \%$} & ROD1 & $0-500 \mathrm{~m}$ & . /R R. & .1094 & .194 & \multirow{4}{*}{ FLT } & \multirow{4}{*}{$\because \cdot r$} & FLT1 & $0-1500 \mathrm{~m}$ & $-\cdot / \cdot V Y Y$ & $\cdot / \cdot 1$ & $\%$ \\
\hline & & ROD2 & $500-1000 \mathrm{~m}$ & $\cdot /$ /vo. &.$/ Y 9 V$ & $\cdot / \cdot \vee \wedge$ & & & FLT2 & $1500-3500 \mathrm{~m}$ & $-\cdot / \cdot V \vee \Delta$ & .1 .94 &.$/ \cdot 1$ \\
\hline & & ROD3 & $1000-5000 \mathrm{~m}$ & $\cdot / .9 .9$ & $\cdot / 1 \cdot 1$ & $\cdot / . \mu 1$ & & & FLT3 & $3500-5000 \mathrm{~m}$ &.$- / . r \wedge q$ &.$/ Y 9 V$ & .1 .49 \\
\hline & & ROD4 & $>5000 \mathrm{~m}$ &.$/ r \Delta r$ & .1 .94 & $\cdot / \cdot 11$ & & & FLT4 & $>5000 \mathrm{~m}$ & - & $\cdot / 094$ &.$/ .14$ \\
\hline \multirow{4}{*}{ DRN } & \multirow{4}{*}{$119 \%$} & DRN1 & $0-250 \mathrm{~m}$ & . &.$/ V^{4}$ & $\cdot / . \mathrm{r}$ & \multirow{4}{*}{ RNG } & \multirow{4}{*}{$\cdot .1 T V$} & RNG1 & بدون بوشش & $\cdot$ &.$/ 191$ & $.1 . r^{9}$ \\
\hline & & DRN2 & $250-500 \mathrm{~m}$ & . &.$/ 1 V^{4}$ & $\cdot / \cdot r$. & & & RNG2 & فقير | لمقر & \%.ATr &.$/ 099$ & $\cdot / \cdot \Delta Y$ \\
\hline & & DRN3 & $500-1000 \mathrm{~m}$ &.$/ 1.09$ & $\cdot / \Delta \mathrm{N} 1$ &.$/ .9 \mathrm{~V}$ & & & RNG3 & خيلي فقير & - & $\cdot / 1 \cdot V$ & .1 .10 \\
\hline & & $\begin{array}{l}\text { DRN4 } \\
\end{array}$ & $>1000 \mathrm{~m}$ & $-\cdot / \cdot Y Y A$ & $\cdot / \cdot V 1$ & $\cdot / \cdots 1$ & & & RNG4 & غني | ل غني & . & $\cdot \pi \cdot v$ &.$/ .10$ \\
\hline \multirow{3}{*}{ RAN } & \multirow{3}{*}{$\cdot r y /$} & RAN1 & $450-650 \mathrm{~mm}$ & - & $\cdot / 4 \Delta \Lambda$ & $\cdot / \cdot 1$ & \multirow{8}{*}{ ASP } & \multirow{8}{*}{.$r 4 \%$} & ASP1 & $\mathrm{E}$ &.$- / .194$ &.$/ . r q$ & 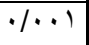 \\
\hline & & RAN2 & $650-850 \mathrm{~mm}$ &.$- / . r \Delta V$ & $\cdot / 1 r^{4}$ & $\cdot \cdot \cdot r$ & & & ASP2 & $\mathrm{N}$ & . & $\cdot / V V^{\prime}$ & .1 .94 \\
\hline & & RAN3 & $850-1000 \mathrm{~mm}$ & - & $\cdot / 419$ & $\cdot / \cdots 9$ & & & ASP3 & $\mathrm{NE}$ & $\cdot \% \vee \vee \wedge \wedge$ & $\cdot / 4 \cdot 9$ & $.1 \cdot 14$ \\
\hline \multirow{5}{*}{ SLP } & \multirow{5}{*}{$.0 /$} & SLP1 & $0-15 \%$ &.$/ . \Delta T \Delta$ & $\cdot / \Delta T Y$ & $\cdot / \cdot Y V$ & & & ASP4 & $\mathrm{NW}$ & - & $\cdot 1 \cdot \sqrt{ }{ }^{4}$ & $\%$ \\
\hline & & $\begin{array}{l}\text { SLP2 } \\
\end{array}$ & $15-25 \%$ & $\% \cdots \wedge$. & .1199 & $\cdot / \cdots 1$ & & & ASP5 & $\mathrm{S}$ & . & $\cdot 1 \cdot \sqrt{94}$ & $\%$ \\
\hline & & SLP3 & $25-40 \%$ & $\cdot / \cdot r$. & . & $\cdot / \cdot \cdot v$ & & & ASP6 & SE & $-\because / \cdot Y \mid Y$ &.$/ . r q$ &.$/ .1$ \\
\hline & & SLP4 & $40-70 \%$ & - & $\cdot \%$. N & 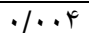 & & & ASP7 & SW & $.1 \times Y Y 4^{4}$ & $\cdot / \lambda \cdot$ & .1 .94 \\
\hline & & $\begin{array}{l}\text { SLP5 } \\
\end{array}$ & $>70 \%$ & - & $\cdot \% \wedge r$ & $\cdot \ldots+$ & & & ASP8 & $\overline{\mathrm{W}}$ & -.1 .9999 &.$/ .19$ &.$/ .1$ \\
\hline \multirow{11}{*}{ LIT } & \multirow{11}{*}{ ror $\%$} & LIT1 & بختياري &.$- / . r 41$ & $\cdot / \cdot 1 \mathrm{~V}$ & $\cdot \cdots \varphi$ & \multirow{11}{*}{ LUS } & \multirow{11}{*}{$\cdot \vee \wedge \wedge /$} & LUS1 & كثاورزي & . / Nr. &.$/ 201$ & $\cdot / \cdot r$ \\
\hline & & LIT2 & ميلا & $.0 .4 T r$ &.$/ 119$ &.$/ . r$. & & & LUS2 & باغ باغ باغ & -.1 .449 &.$/ .19$ &.$/ \ldots 1$ \\
\hline & & LIT3 & كثكان & $\cdot$ &.$/ .01$ &.$/ .14$ & & & LUS3 & مرتع خوب & $.1 .4 \wedge 9$ &.$/ 4$. &.$/ .11$ \\
\hline & & LIT4 & سورمه & • & .1 .01 &.$/ .14$ & & & LUS4 & 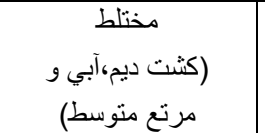 & •.Ar &.$/ 201$ & $\%$. r. \\
\hline & & LIT5 & كوريي & - & .1 .01 &.$/ .14$ & & & LUS5 & 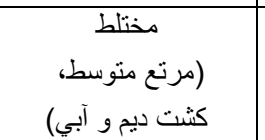 &.$/ . T H A$ & $\cdot / \cdot r$ & $\%$. \\
\hline & & LIT6 & ايلام &.$- .1 \cdot 111$ & ..$Y Y$. & .1 .94 & & & LUS6 & مرتع متوسط & - & $\cdot / \cdot \varphi v$ & $\cdot / \cdots 4$ \\
\hline & & LIT7 & إيلام_ سروك & . & $.1 .0 \cdot 0$ &.$/ .14$ & & & LUS7 & مرتع فقير &.$- / \cdot Y \cdot \Delta$ & $\cdot / \cdot r)$ & $\cdot \% r$ \\
\hline & & LIT8 & كوريبي r & $.1 \cdot 9 \cdot 4$ & $\cdot / 4 \cdot 49$ &.$/ . \Delta r$ & & & LUS8 & شهر &.$- / \cdot 1 \Delta V$ & $\cdot / \cdot r)$ & $\cdot \% r$ \\
\hline & & LIT9 & كو اترنر & $\cdot / \cdot 9 \cdot 1$ & . &.$/ \cdot \Lambda 4$ & & & LUS9 & مختلط (كثت ديم و آبي) & $\cdot$ & $\cdot / \cdot \varphi v$ & 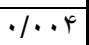 \\
\hline & & $\begin{array}{l}\text { LIT10 } \\
\end{array}$ & داريان & . & .1 .0 .0 &.$/ \cdot 14$ & & & LUS10 & سنى & . &.$/ \cdot \varphi v$ &.$/ .+\varphi$ \\
\hline & & LIT11 & داريانـ فهليان & . & $.1 .0 \cdot 0$ &.$/ .14$ & & & LUS11 & مختلط (زراعت و باغ) & . &.$/ \cdot 4 \mathrm{~V}$ & $\cdot / \cdot \varphi^{4}$ \\
\hline
\end{tabular}

جدول V. كسترههاى لغزشى حوضه رودخانه ماربر در روش تحليل سلسلهمراتبى

\begin{tabular}{|c|c|}
\hline كسترههاى با حساسيت خيلى كم & $\cdot / \cdot V F_{-} \cdot / l F T$ \\
\hline كسترههاى با حساسيت كم & $\cdot / K T-\cdot / T$ \\
\hline كَسترههاى با حساسيت متوسط & $\cdot|r-\cdot / T V|$ \\
\hline كَسترهاى با حساسيت زياد & $\cdot / T V I-\cdot / K F V$ \\
\hline
\end{tabular}




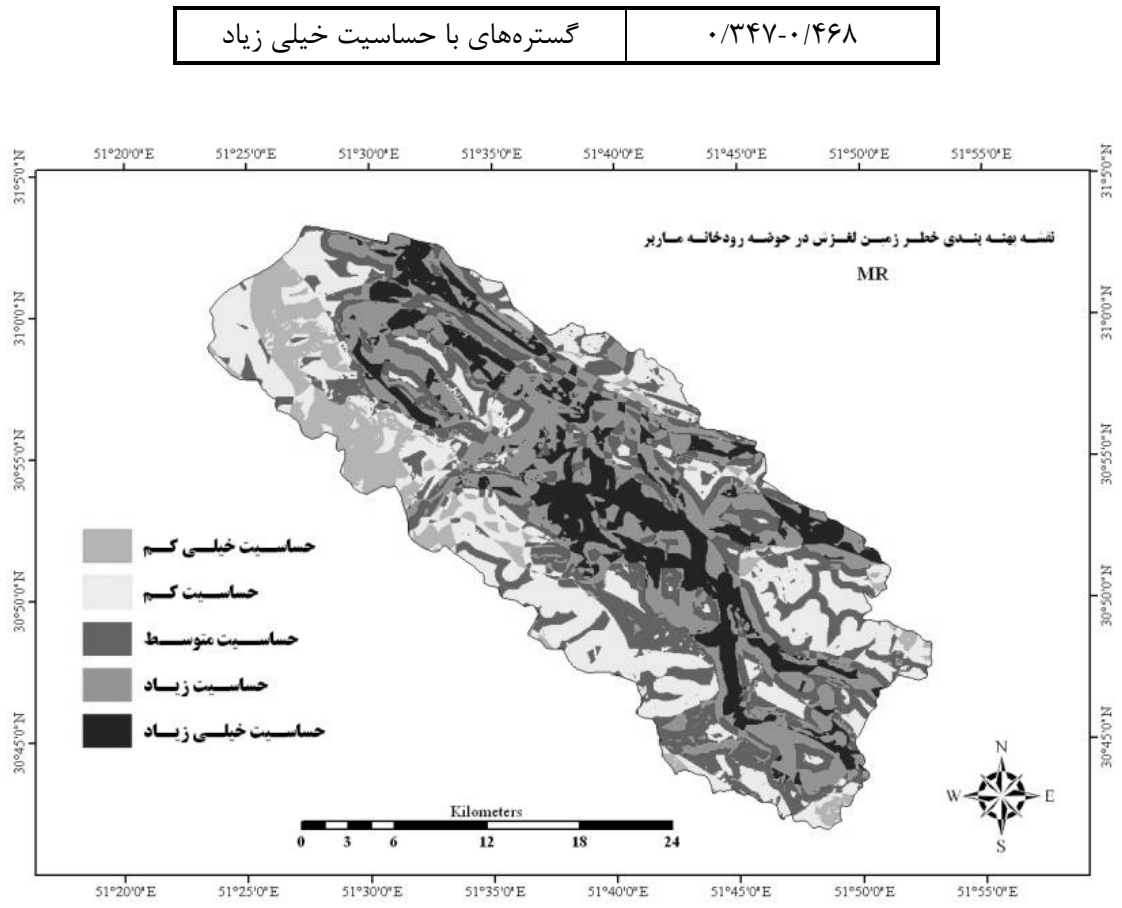

شكل ه. نقشه يههنهبندى خطر رخداد زمينلغزش در روش تحليل سلسلهمراتبى (AHP) با استفاده از ضرايب ركرسيونى

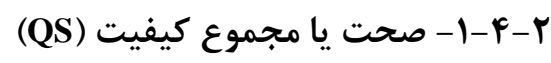

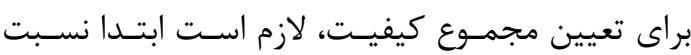
تراكمى محاسبه كَردد، كه اين محاسبه در قالـب رابطــهـ

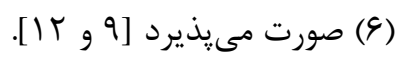

$$
\operatorname{Dr}=\frac{\frac{\mathrm{Si}}{\mathrm{Ai}}}{\frac{\sum_{\mathrm{i}}^{\mathrm{n}} \mathrm{Si}}{\sum_{\mathrm{f}}^{\mathrm{n}} \mathrm{Ai}}}
$$

(9) (بطه

كه در آن: Si = مجموع مساحت زمـينلغـزشهـاى

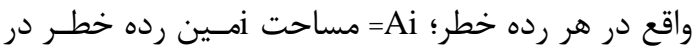
يك نقشه يهنهابندى؛ و n = تعداد ردههاى خطر.

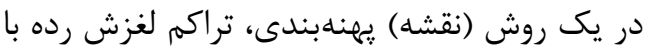
معادل با متوسط تراكم لغـزش در كـل منطقــه و رده داراى نسبت تراكمى كا، داراى تراكم لغزشى معـادل

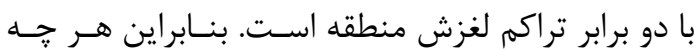

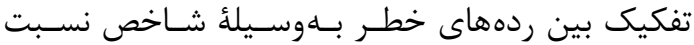

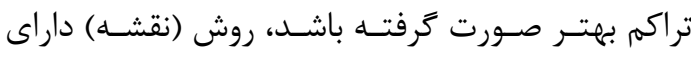

Y-Y - - صحتسنجى و مقايسه روش هاى مورد استفاده

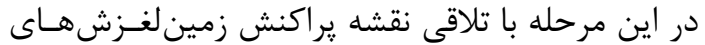

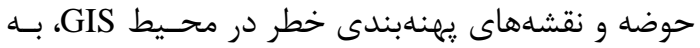

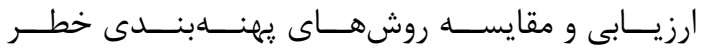

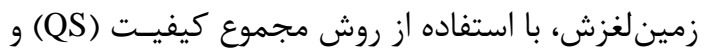

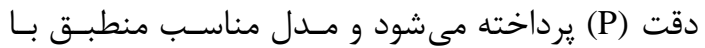

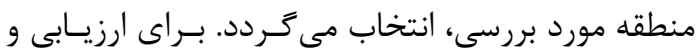

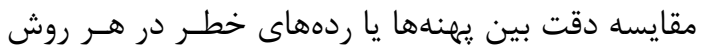

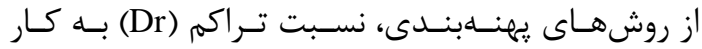

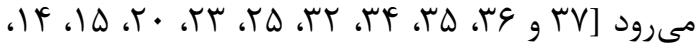
[t.

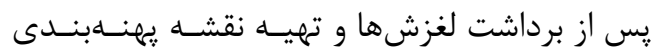
خطر زمين لغزش به روشهاى آمارى حندمتغيره (MR)

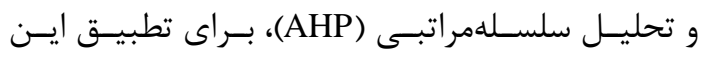
نقشهها با نقشه واقعيت زمينى و مقايسه آنها با يكديكر،

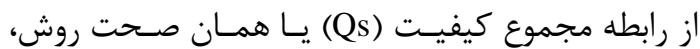

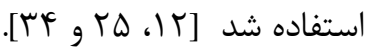


نتايج حاصل از يردازش به صورت كمّى ارائسه مسىشـود.

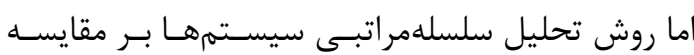

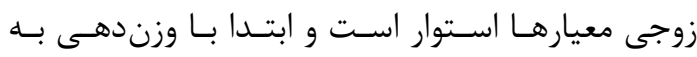

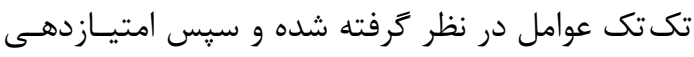

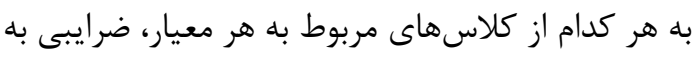
دست مى آيند كه مدل نهايى براساس آنها ارائه مى خرّرد

[س دست

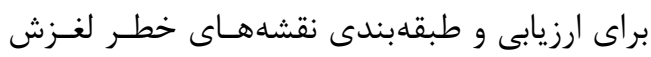

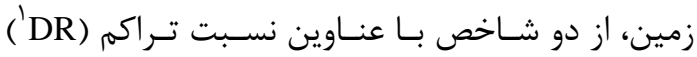

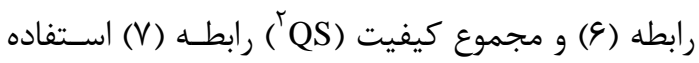

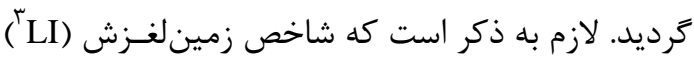

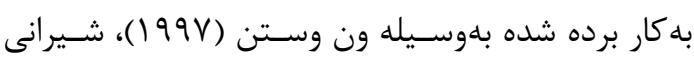

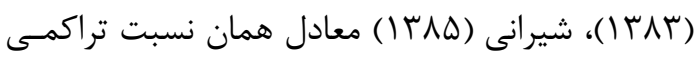
(Dr)

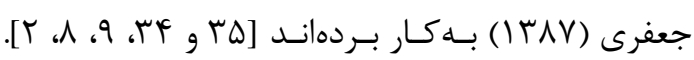

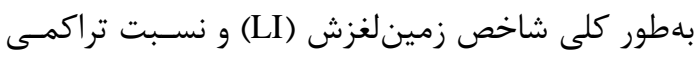

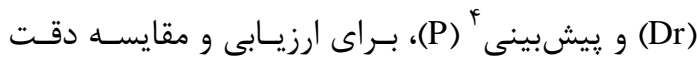

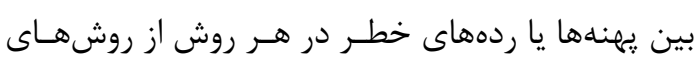

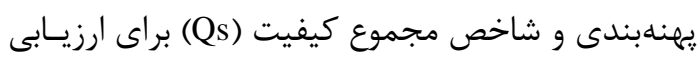

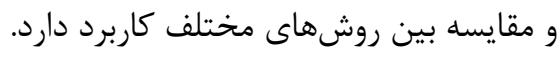

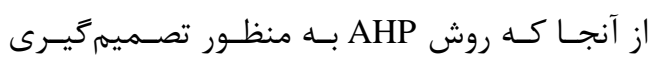

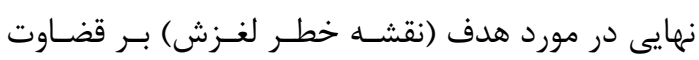

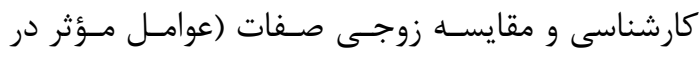

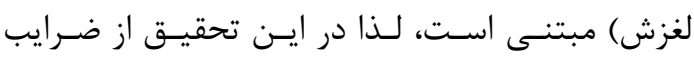

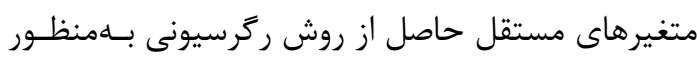

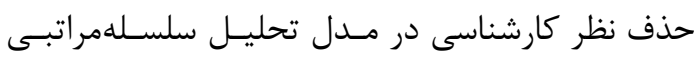

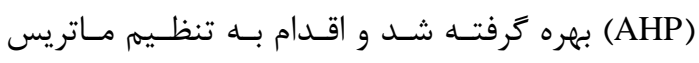

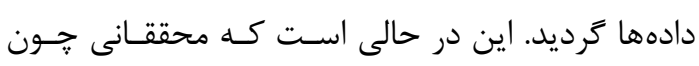

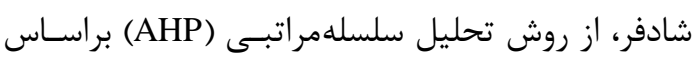
قضاوت كارشناسى استفاده كردهاند [بrآ].

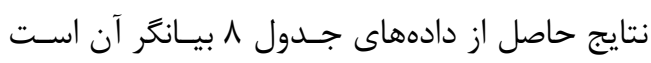

1. Density Ratio

2. Quality Sum

3. Landslide Index

4. Results Precision of the Predicted

$$
\text { دقت يا مطلوبيت بيشترى است. }
$$

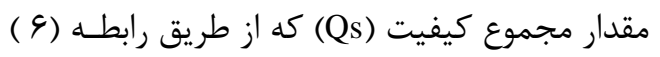

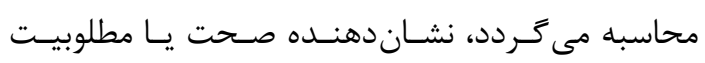

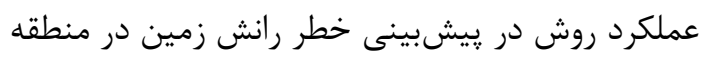

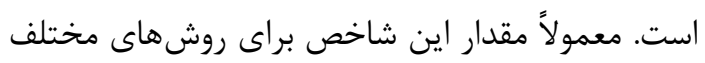

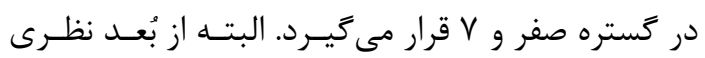

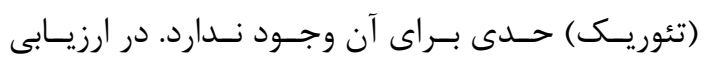

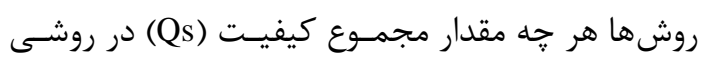

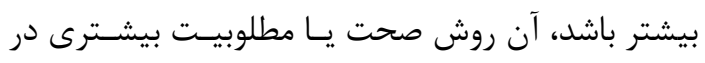

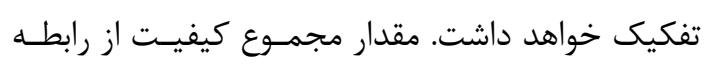

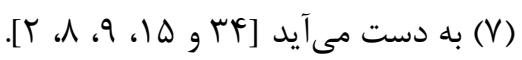

$$
\text { رابطه (V) }
$$

$$
\begin{aligned}
& \mathrm{Qs}=\sum_{\mathrm{i}=1}^{\mathrm{n}}\left((\mathrm{Dr}-1)^{2} \times \mathrm{S}\right) \\
& \text { مجموع كيفيت؛ Dr= نس نسبت تراكم؛ S= نسـبت } \\
& \text { مساحت هر رده خطر به مساحت كل منطقه؛ و و } \\
& \text { n = تعداد كلاس خطر } \\
& \text { (P) عار }
\end{aligned}
$$

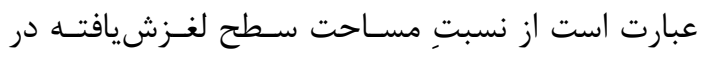

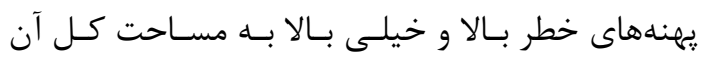

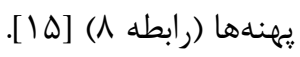
$\mathrm{P}=\mathrm{KS} / \mathrm{S}$
رابطه (ᄉ)

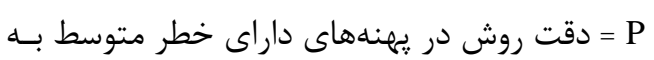

KS

خطر متوسط به بالا

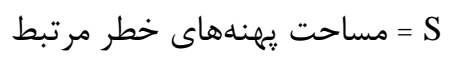

\section{ب- بنتايج و بحث}

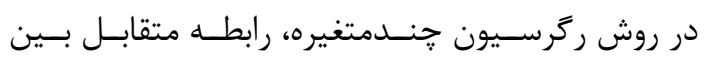

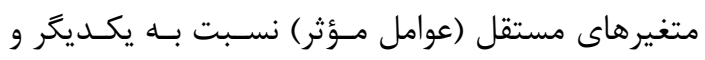

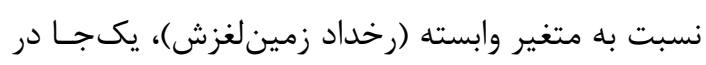
نظر كرفته مىشود [rr]]. در اين روش دادههاى اوليـه و 


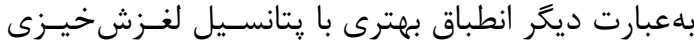
منطقه خواهد داشت. در اين مورد روش سلسلهمراتبسى دئس

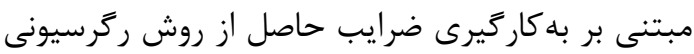
(روش تلفيقى)، بهرغم موارد پِيش كفته، بهدليل مقايسه

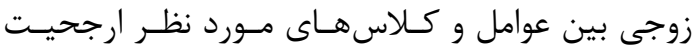

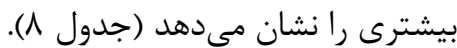

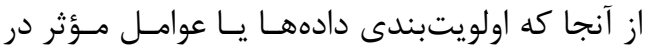
مــد AHP بــهـ صـورت قضـاوت كارشناسـى تعيـين

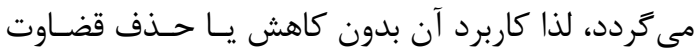
كارشناسى، موجب به دست آمدن برآوردهاى نادرسـى از رخداد خطر زمينلغزش خواهد شد. محدوديت تكنيكى و يردازشى در به كاركيرى صرفي مدل ركرسيونى با استفاده از دادههاى بيوسته و رويكرد

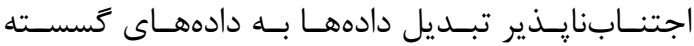

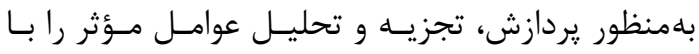

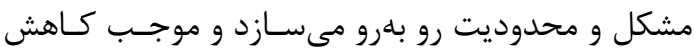

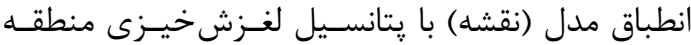

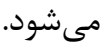

ردهبندى متفـاوت مــدل نهايى از نظـر حساسـيت لغزشى، در صورتى كه از روال مشخصى در تعيين حدود

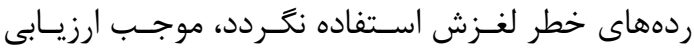
نادرست از مدل مورد استفاده خواهد كرديد. بــهــــــــان مثال عدم توجه به نقاط عطف منحنى تجمعسى فراوانى مساحت لغزشها نسبت به مساحت كل هر رده خطر.

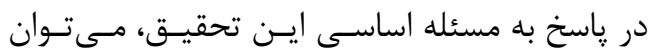

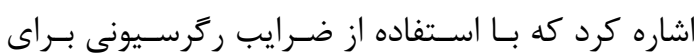

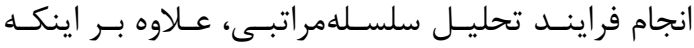
مى توان نقش هر عامل را بر لغـزش بررسـى كـرد بلكـهـ

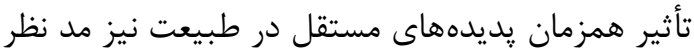

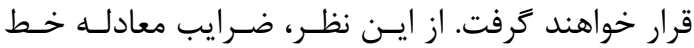
ركرسيونى برازش داده شده، به عنوان وزن كمّى عوامل

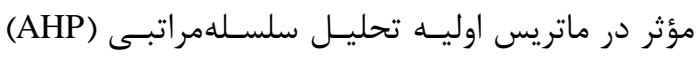

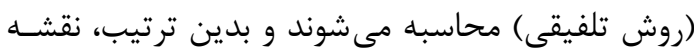
نهايى خطر زمين لغزش، انطبـاق بيشــــى بـا ٍتانســيل

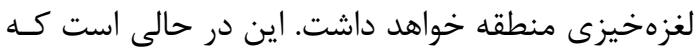

كه در هر دو روش، نسـبت تراكمى (Dr) ـ كـه همـان

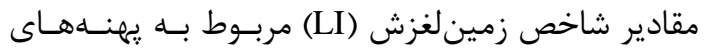

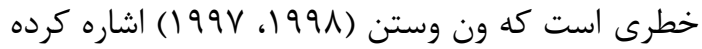

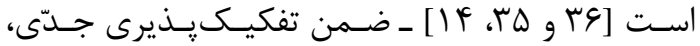
متناسب با افزايش خطر يهنـهـهـا، رو بـه فزونسى نهـاده

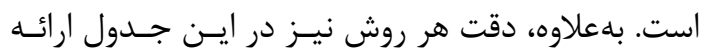

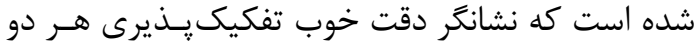
روش است كه در مورد روش ركرسيونى مؤيســ تحقيـق

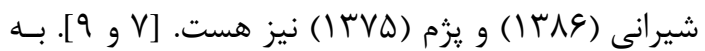
علاوه، همان طور كـه در جـدول 9 آمـده اسـت، مقـدار

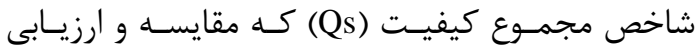

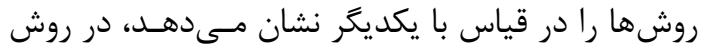

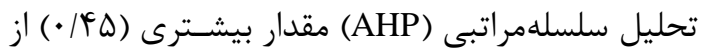

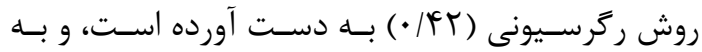
عبارت ديخر مطلوبيت بهترى دارد. اين در حسالى اسـت

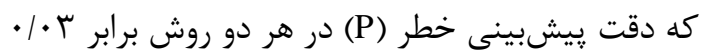

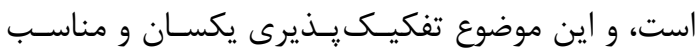
يهنههاى خطر را نيز تأييد مى كند.

\section{F- نتيجه Fيرى و ييشنهادها}

با توجه به سوابق تحقيق، نتايج حاصل از مدلسازى بـا

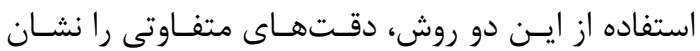

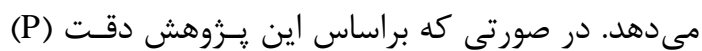

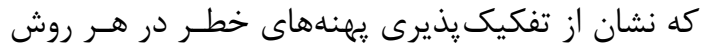

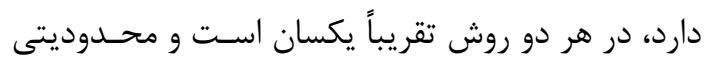

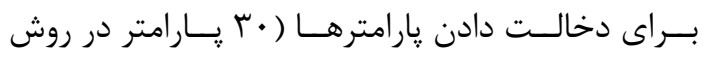

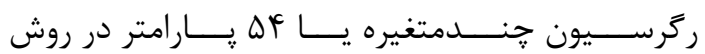
سلسلهمراتبى) به جشم نمى خورد. اختلاف در صحت يا

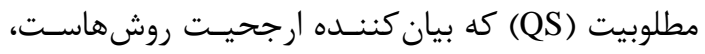

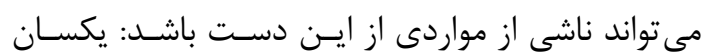

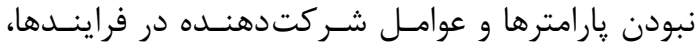
هنكًامى كه هدف همانا مقايسه باشد. بـهعبـارت ديخـر،

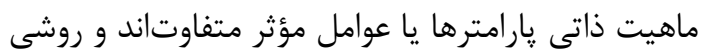

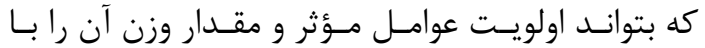
همديكر محاسبه كند، داراى صـحت بيشـترى اسـت، و ولنوان 
رخداد زمين لغزش مؤثر بوده است.

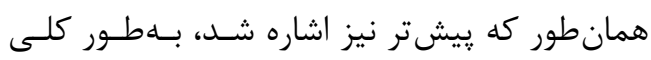

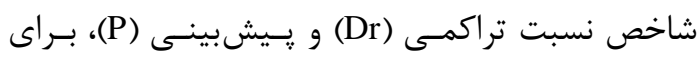

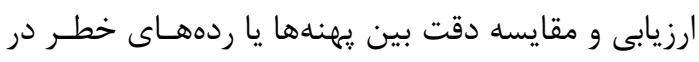

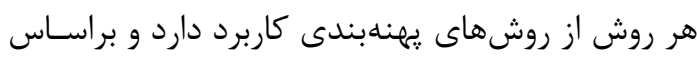

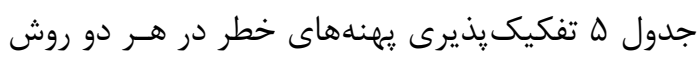

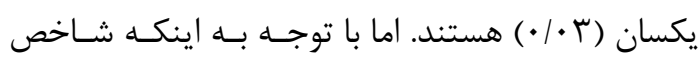

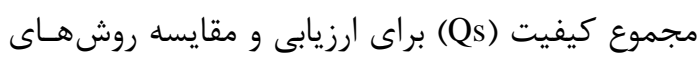

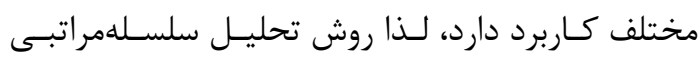

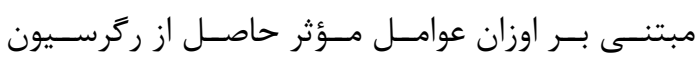

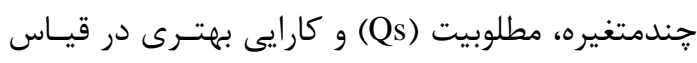
با روش ركرسيونى در منطقه مورد مطالعه دارد.
محققان يِيشـين، صـرفاً از دو روش مـذكور بـهـ صـورت

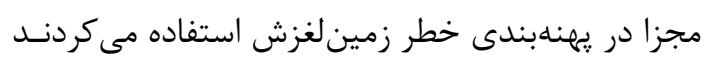
و به مقايسه آنها با همديخر مى يرداختند.

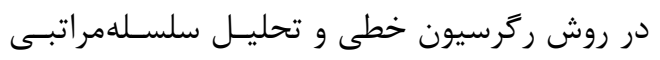

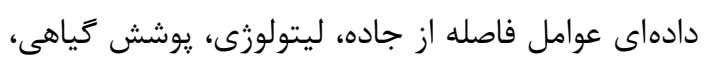

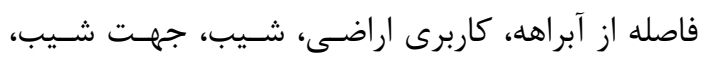

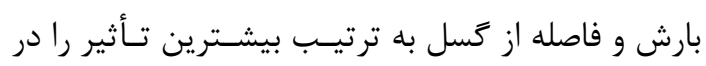
رخداد زمين لغزش داشتهاند.

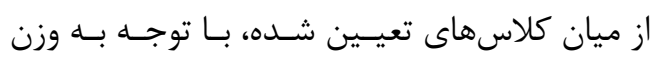

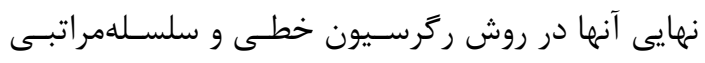

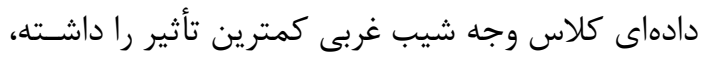

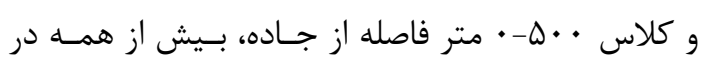

جدول ^. صحت و دقت روشهاى يهنهابندى خطر زمينلغزش در منطقه مورد بررسى

\begin{tabular}{|c|c|c|c|c|c|c|c|c|}
\hline يهنهدبندى مدل & ردبت بهاسيت خطر & $\begin{array}{c}\text { مساحت } \\
\text { مسهنه } \\
\left(\mathrm{Km}^{r}\right)\end{array}$ & $\begin{array}{c}\text { مساحت لغزش } \\
\text { مسهنه } \\
\left(\mathrm{Km}^{r}\right)\end{array}$ & نسبت & (S) درصد & $\begin{array}{l}\text { درهر } \\
\text { رده }\end{array}$ & $\begin{array}{l}\text { كجيفيت } \\
\text { مجموع }\end{array}$ & دوشت \\
\hline \multirow{6}{*}{ AHP } & خيلى كم & $99 / \pi$. & rT/. & . & .1 .9 & $\cdot / \cdot \Delta$ & \multirow{5}{*}{$\cdot / 4 \Delta$} & \multirow{5}{*}{.} \\
\hline & كم & $r \cdot V / F \Lambda$ & $1 / T \Delta$ & $\cdot / / 9$ & $\cdot / \pi G$ & . & & \\
\hline & متوسط & $r \cdot r / \Delta V$ & $r / \Delta l$ & $\cdot / \Lambda F$ & $\cdot / \pi \Delta$ & $\cdot 1 \cdot 1$ & & \\
\hline & زياد & $\mid r T / G \Lambda$ & $\Delta / F F$ & $1 / 4 \lambda$ & $\cdot / \Delta \Delta$ & .1 .9 & & \\
\hline & خيلى زياد & $19 V / 1 T$ & $8 / . r$ & $r / \Lambda \Delta$ & $\cdot / \pi \Delta$ & $\cdot / T$ & & \\
\hline & جمع & $\Lambda \cdots / \wedge \Delta$ & $19 / 0$. & & & & & \\
\hline \multirow{6}{*}{ MR } & خيلى كم & $\mid r M / F \wedge$ & س אוא. &.$/ 19$ & $\cdot / \mathrm{V}$ & .1119 & \multirow{5}{*}{. MT } & \multirow{5}{*}{$\cdot / \cdot r$} \\
\hline & كم & $1 \wedge 9 / \% V$ & T/K & $\cdot / \Delta V$ & $\cdot / R F$ &.$/ \cdot k r$ & & \\
\hline & متوسط & $19 \cdot / 41$ & 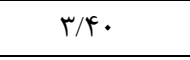 & $\cdot / A V$ &.$/ M F$ & $.1 \cdot r$ & & \\
\hline & زياد & $1 \cdot r / r \mu$ & $Y / N$ & $1 / \Delta 1$ & rאו & $\cdot / \cdot \Delta q$ & & \\
\hline & خيلى زياد & $1 \wedge F / \Delta q$ & $\Delta / V r$ & T/Tr & ./I &.$/ 194$ & & \\
\hline & جمع & $\Lambda \cdots / \wedge \Delta$ & $19 / 0$. & & & & & \\
\hline
\end{tabular}

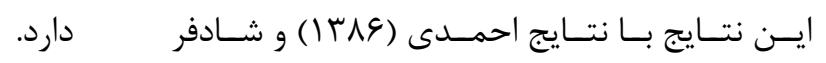

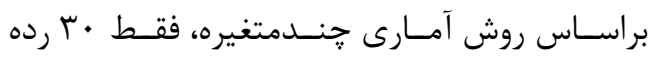

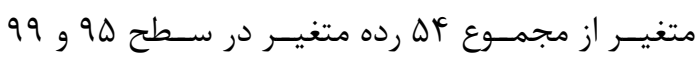

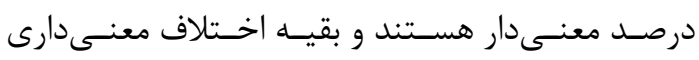

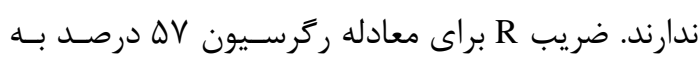

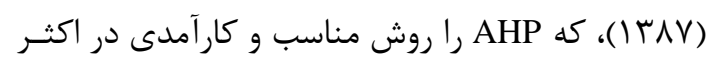

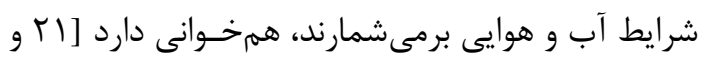

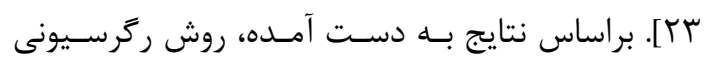

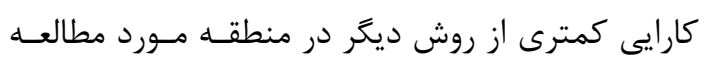


[4] Ramesht, M.H., 1996. Application of Geomorphology In Regional National and Economic Planning. first printed, University of Esfahan, 268.

[5] Alesheikh, A., Vahidnia, M.H., Alimohammadi, A. and Hosseinali, F., 2009. Landslide Hazard Zonation Using Quantitative Methods in GIS. International Journal of Civil Engineerng, 7(3), 176-189.

[6] Behnyafar, A., Ghanbarzadeh, H. and Mansouri, M.R., 2009. Landslide Hazard Zonation and Unstable Slope by AHP Methods and Probability (case study: basin Kong River, northern slopes Binalud). Journal of geographical space, Azad University, Ahar, 37, 55-78.

[7] Pezham, M., 1996. Mass Movements Hazard Zoation in Alamoutrood Watershed. M.Sc. of Abkhizdari, Natural Resources Faculty, University of Tehran.

[8] Shariat Jafari, M., Ghayomian, J., 2008. Evaluation of Bivariate Statistical Analysis Models in Sandslide Hazard Zonation. Tehran University Journal, 34 (1), 137-143.

[9] Shirani, K., Ghayomian, J., and Mokhtari, A., 2005. Evaluation of Bivariate and Multivariate Statistical Methods in Landslide Hazard Zonation. Journal of Water and Watershed, Soil Conservation and Watershed Management Research Institute, 2(2), 36-48.

[10] Safai, J., Onagh, M., Mesdaghi, M. and Shariat Jafari, M., 2009. Empirical and Statistical Models to Compare Performance Landslide Hazard Zonation (case study: watershed Alamut River). Journal of Soil and Water Conservation Research, 16(4), 35-45.

[11] Geraei, P., Soleimani, K., Mousavi S.R. and Kaviyan, A., 2009. Landslide Hazard Regional Modelling by Using Multivaration Regression Statistical Method in Lajimrood Watershed of Sari. Journal of Earth Sciences, 73, 29-36.

[12]Gee, M.D., 1992. Classification of

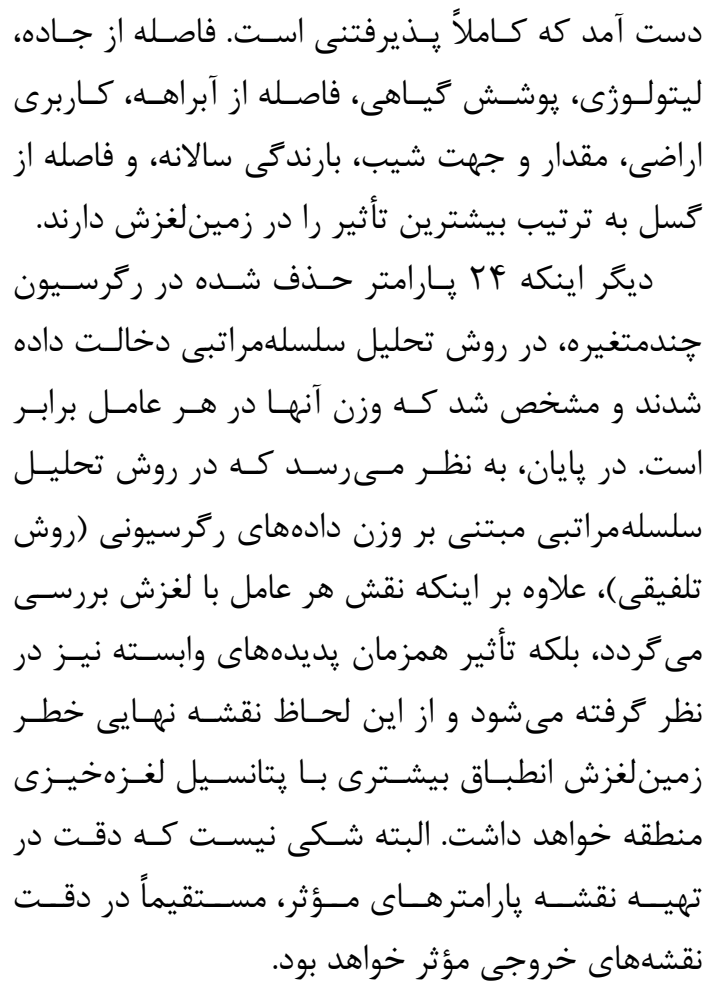

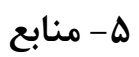

[1] Emami, S. and Ghayomian, J., 2003. Investigation on the Mechanism on the Landslide Rock Fall, Case Study: Afsrabad Landslide in Chaharmahal and Bakhtiari. In: The Third Conference on Engineering Geology and Environment of Iran, University in Bu Ali Sina Hamedan.

[2] Shirani, K., 2004. Evaluate the Most Important Landslide Hazard Zonation Methods to Select an Appropriate Method for the South of Isfahan Province, Semirom Region. Ministry of Agriculture, Soil Conservation Research Institute, 104.

[3] Cornforth, D.H., 2005. Landslides in Practice. USA: john wiley \& sons Inc, 591.

Landslides Hazard Zonation Methods and a Test of Predictive Capability. In: Bell, Davi, H. (eds.), Proceedings 6th International Symposium on Landslide, 48-56.

[13] Guzzetti, F., Cardinali, M., Relchenbach, P. and Carrara, A., 2000. Comparing Landslide Maps: A Case Study in the Upper Tiber 


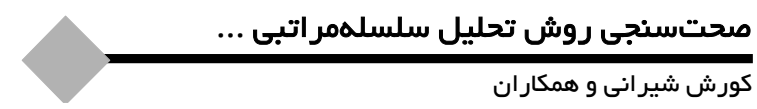

River Basin. Central Italy, Environmental management, 25, 247-263.

[14] Ilwis Applications Guide, 1997. Ilwis 2.1 for Windows. International Institute for Aerospace Survey and Earth Science (ITC), Ensched, Netherlands.

[15] Jade, S. and Sarkar, S., 1993. Statistical Models for Slope Instability Classifications Engineering Geology. 36, 91-98.

[16] Nefeslioglu, H.A., Duman, T.Y, and Durmaz, S., 2008. Landslide Susceptibility Mapping for a Part of Tectonic Kelkit Valley (Eastern Black Sea region of Turkey). Geomorphology, 94 (3-4), 401-418.

[17]Saro, Lee and Kyungduck, M., 2001. Statistical Analysis of Landslide Susceptibility at Yonging. Korea, Environmental Geology, 40, 1095-1113.

[18] Varnes, D.J., 1978. Landslide Type and Processes. In: E. B Eckel, eds.Landslide and Engineering Practice, Special Report NO. 29., Highway Research Board, 20-47.

[19] Varnes, D.J., 1984. Landslide Hazard Zonation a Review of Principle and Practice. Irancel United Nation Educational Scientific and Cultural (UNSSCO) France.

[20] Yin, K.J. and Yan, T.Z., 1988. Statistical Prediction Model for Slope Instability of Metamorphosed Rocks. Proceedings 5th International Symposium on Landslides, Lausanne, Switserland, 2, 1269-1272.

[21] Ahmadi, H., Asmaly, A., Feiznia, S. and Shariat Jafari, M., 2003. Hazard Zonation Mass Movements Using Two Methods of Multiple Regression (MR) and AHP (case study: Garmi chayei watershed). Journal of Natural Resources, Jad 56, 326-323.

[22] Feiznia, S., Klarstaghy, A., Ahmadi, H. and Safaei, M., 2004. Factors Affecting the Occurrence of Landslides and Landslide Hazard Zonation (Case Study: Shirin River Watershed Dam Tajan). Journal of Natural Resources, 57 (1), 3-22.

[23] Shadfar, S., Yamani, M., Ghodousi, J. and
Ghayomian, J., 2007. Landslide Hazard Zonation by Using AHP (case study: watershed Chalkrod Tonekabon). Journal of Research and the Construction of Natural Resources, 75. 118-126.

[24] Alijani, B., Ghohrodi, M. and AmirAhmadi, A., 2007. Landslide Hazard Zonation in the northern Shah Jahan Slopes by Using GIS (Case study: basin Astrkhy Shirvan). Geographical Research Quarterly, 116-131. 84.

[25] AliMohammadi, S., Pashaii aval, A., Shtay Jooybari, Sh. and Parsaei, L., 2009. Iran Efficiency Assessment of Landslide Hazard Zonation in the Watershed Sydklath Rummy. Journal of Soil and Water Conservation Research, 16 (1), p 59-78.

[26] Ownegh, M., 2004. Assessing the Applicabilty of Austalian Landslide Databases for Hazard Management. In: 13th International Soil Conservation Organization Conference, Brisbane, July.

[27]Haghshenas, E., 1996. Landslide Hazard Zonation and Relationship Its to Sediment Yield in Taleghan. M.Sc. Thesis, Tarbiyat Modares university.

[28] Sadoaldin, A., 1993. Investigation of Hydrogeomorphologic Parameters Effects on Mass Movements Slope Matter in Chasham-khatirkouh watershed of Semnan. M.Sc. Thesis, Tarbiyat Modares university.

[29] Movahed Danesh, A.A., 1994. Hydrology of Surface waters of Iran. Tehran: Samt Publication.

[30] Water project of Iran, 1999. Karoon Basin Report. Consulting engineers company of Jamab related to Niro ministry.

[31] Masodian, A. and Kaviani, M., 2007. Climatology Iran, Isfahan: University of Isfahan press.

[32] Nagarajan, R., Roy, A., Vinodkumar, R., Mukherjee, A. and Khire, M.V., 2000. Landslide Hazard Susceptibility Mapping based on Terrain and Climatic Factors for Tropical Monsoon Regions. Bull. Eng. Geol. Env. 58. 
[33] Ghodsipour, S.H., 2009. Analytical Hierarchy Process (AHP). Tehran: Amirkabir university Publication.

[34] Shirani, K., Chavoshi, S. and Ghayomian, J., 2006. Evaluation of Methods for Landslide Hazard Zonation in the Uptown Padena Semirom. Research Journal of Sciences, Isfahan University, 23(1), 23-38.

[35] Van Westen, C.J., Rengers, N., Terline, M.T.J. and Soeters, R., 1997. Predication of the Occurrence of Slope Instability Phenomena through GIS-Based Hazard Zonation. Geologisches Rundschau, 86, 404-414.
[36] Van Westen, C.J. 1998. Geographic Information Systems in Slope Instability Zonation (GISSIZ), Volume I, II.

[37] Yalcin., A., 2008. GIS-based Landslide Susceptibility Mapping Using Analytical Hierarchy Process and Bivariate Statistics in Ardesen (Turkey), Comparisons of results and confirmations Catena, 72, 1-12. 


\title{
Accuracy Investigation of Analytical Hierarchy Process (AHP) and Multivariate Regression (MR) Methods in Landslide Hazard Zonation, Using GIS (Case Study: Marbor River Basin)
}

Shirani K. ${ }^{1 *}$, Saif A. ${ }^{2}$, Alimoradi M. ${ }^{3}$

\author{
1. Ph.D. Candidate, Geomorphology Dep., Geographic Sciences Faculty, University of Isfahan \\ 2. Assistant Prof. Geomorphology Dep., Geographic Sciences Faculty, University of Isfahan \\ 3. M.Sc. of Geomorphology Dep., Geographic Sciences Faculty, University of Isfahan
}

\begin{abstract}
A combination of natural and human factors have caused numerous landslide related damaged. One of the main strategies for reducing the damages of landslides is to avoid these regions. For this purpose it is necessary to be prepared landslide hazard zonation map precisely among available methods for these areas. At first, the object of this research is the relative weight determination of effective parameters, using Multivariate Regression (MR) in substitute of parameters priority in Analytical Hierarchy Process (AHP). For implementing this research, first of all, by aerial photos and satellite images, geological maps and studies of the field by using GPS, landslide inventory map in Marbor River Basin (sub-basin of the upper part of North Karoon Basin), an 800 square kilometers area located on the lower part of Southern Isfahan province, were prepared. By Using field studies and reviewing the related studies about similar areas with basins of Karoon and Dez Upper North and the existing thematic maps, 9 factors including lithology, slope, land use, rainfall, vegetation, aspect, and lineaments elements, containing fault and drainages, the action of factors in determining landslide (54 parameters in the consist of eight main factors) were measured. For the purpose of enhancing accuracy, accelerating and easing the analysis, all spatial and descriptive data entered into GIS system and were overlayed ArcGIS version9.3 software as vector. By overlaying these maps, 27466 homogeneous units were resulted, that were based upon calculating two methods including MR an AHP related to Multivariate decision analysis the results of analysis showed that both methods have almost had the same accuracy in separation landslide hazard zones, and the landslide hazard index was obvious too. Of course, it should be noticed that hierarchical approach based on regression data, on the basis the sum of quality index as an indicator of the accuracy, is more desirable.
\end{abstract}

Keywords: Landslide, Hazard zonation, Marbor watershed, Multivariate regression, Analytical Hierarchy Process, GIS.

* Correspondence Address: Isfahan Center for Rescearch of Agricultural science and Natural Resources, Amirhamzeh, Isfahan Tel: 09133137356

Email: k-sh424@yahoo.com 